\title{
WHO LIVES, WHO DIES, WHO TELLS YOUR STORY? \\ HAMILTON AS A CASE STUDY FOR MUSICAL MNEMONICS
}

\author{
by \\ Sabrina Guillen \\ Bachelor of Arts in English Literature \& History \\ University of Waterloo, 2020 \\ A MRP presented to Ryerson University \\ in partial fulfillment of the \\ requirements of the degree of \\ Master of Professional Communication \\ in the program of \\ Professional Communication
}

Toronto, Ontario, Canada, 2021

(C) Sabrina Guillen, 2021 


\section{AUTHOR'S DECLARATION}

I hereby declare that I am the sole author of this MRP. This is a true copy of the MRP, including any required final revisions

I authorize Ryerson University to lend this MRP to other institutions or individuals for the purpose of scholarly research

I further authorize Ryerson University to reproduce this MRP by photocopying or by other

means, in total or in part, at the request of other institutions or individuals for the purpose of scholarly research

I understand that my MRP may be made electronically available to the public. 


\begin{abstract}
The study of musical mnemonics arose as an attempt to understand why and how music triggers the human brain in such profound ways. Decades of scholarly research have uncovered the complex interplay between music and human brain processes in ways that are able to elicit unique responses, particularly in individuals suffering from neurodegenerative diseases, learning disabilities, or other sensory anomalies. Previous research has demonstrated that music has inherent structures capable of improving retention, recall, language decoding, general cognitive processes, and in some ways, intelligence. These heightened brain processes have been found to be particularly well suited in enhancing learning capabilities in academic settings. However, there is a significant gap in the literature about how musical mnemonics are employed and engaged within live entertainment, such as musicals, to create dynamic cognitive experiences, as well its applications and efficacy within learning environments (i.e., modulated history instruction supplemented with arts-based field trips).
\end{abstract}




\section{ACKNOWLEDGEMENTS}

Toronto is in the 'Dish With One Spoon Territory'. The Dish With One Spoon is a treaty between the Anishinaabe, Mississaugas and Haudenosaunee that bound them to share the territory and protect the land. Subsequent Indigenous Nations and peoples, Europeans and all newcomers have been invited into this treaty in the spirit of peace, friendship and respect. 
Front Matter

\section{CONTENTS}

Author's Declaration

Abstract

Acknowledgements

iv

Contents

Introduction

Literature Review

Methodology and Research Questions

Findings and Discussion

Experiential Music Associations

Educative Musical Theatre Conventions

Crafting a Memorable Narrative through Rap

Strengthening Associations Through Leitmotif

Repetition: How to Make Information Stick

Using Genre to Characterize Historical Figures

Chord Progression and Cadence

Foreshadowing

Evolving Musical Technique to Emulate Progression 36

Act 1 Finale: Musical Theatre's Recap $\quad 37$

Mapping Music onto Human Speech $\quad 37$

The Power of Words $\quad 38$

Bridging Emotional Reactions: Dissonance $\quad 40$

How to Subvert Expectations for Entertainment $\quad 42$

Rap and Hip-hop as Vehicles for Teaching American Culture 43

Hamilton Teaches Hip-hop Culture 44

Genre as Both Content and Form 46

Rap: An Effective Historical Discourse $\quad 51$

Redefining Mainstream Culture $\quad 52$

Positive Benefits of Arts-Based Field Trips

Teaching Historical Narrative $\quad 56$

Musically Connecting Past and Present $\quad 57$

Reflection on Historiography $\quad 58$

\begin{tabular}{lc} 
Conclusion & 64 \\
\hline
\end{tabular}

\begin{tabular}{lr} 
References & 66 \\
\hline
\end{tabular} 


\section{INTRODUCTION}

Spanish philosopher and writer George Santayana once said: "Those who cannot remember the past are condemned to repeat it" (Santayana, 1980). Santayana expresses a sentiment that has driven historical studies for centuries. History is in its very essence the attempt to understand humanity's past to better inform present and future decisions. But as a subject that attempts to cover periods of time far vaster than the average human lifespan, the challenge of how to develop engaging teaching methods for a modern audience remains. In lieu of traditional forms of history education, entertainment ranging from live theatre to motion pictures to recorded music has attempted to revitalize this field of study. The main question that entertainers and creators alike are trying to address is how to integrate history into contemporary culture in a more fulsome way and elevate the value of history for the broad public?

Live theatre, whether it be plays or musicals, has been a fulcrum for information dissemination through entertainment. Historical musicals, such as Hamilton (2015), Evita (1978), Elisabeth (1992) or even Newsies (1992), have taken this one step further by crafting narratives focused on history and the processes surrounding its recording and retelling. These types of musicals thus not only contribute to the entertainment of their audiences, but also to their education. Historical musicals utilize musical mnemonics to improve an audience's understanding of the viewed historical content while also provoking critical thought on the concepts of historical narrative or historiography. Due to its overwhelming popularity and innovative fusion of hip-hop and rap with historical content, Hamilton (2015) is an apt case study for exploring the relationship between music and musical mnemonics and the communication of narratives as well as the potential educational benefits of incorporating live theatre into school curriculum. 
While certainly not the only reason, a key factor underlying popular aversion to history (beyond a waning interest in humanities in general at all education levels) is that the volume of content can seem quite overwhelming, requires enhanced memorization skills, and often just does not come to life off of the pages of the history books (Lewin, 2014). The struggle for educators and historians alike then becomes how to maintain interest in history for society's benefit, as suggested by Santayana. Part of the solution may be mnemonic devices, which are tools and techniques for condensing information and facilitating learning through associations, which have been widely used in teaching circles for many years to aid memorization. Popular examples include learning which months have how many days on one's knuckles (e.g. knuckle months have 31 days whereas the spaces between knuckles do not) or which planets are in the solar system with the phrase, "My very educated mother just served us nine pizzas" (if one includes Pluto, of course). While mnemonics are commonly used in primary education, once students enter high school they are usually expected to develop their own learning and memorization techniques while teachers adopt a more general lecturing approach. Regardless of one's personal introduction to mnemonics, they are a vital part of one's toolkit for memory and compression with endless applications.

Much untapped potential lies in a subfield of mnemonics, specifically musical mnemonics. This is a memory device which associates information with tunes, lyrics or music and is yet another way that students can digest larger stores of knowledge and recall them accurately. The field of musical mnemonics arose as an attempt to understand why music triggers the human brain in such profound ways. Decades of scholarly research have uncovered the complex interplay between music and human brain processes in ways that are able to elicit unique responses, particularly in individuals suffering from neurodegenerative diseases, learning 
disabilities, or other sensory anomalies. Research has shown that music has inherent patterns and structures capable of improving retention, recall, language encoding/decoding, emotional processing, general cognitive functions, and in some ways, intelligence (Deason, 2018; Rainey \& Larsen, 2002; Chazin \& Neuschatz, 1990; McElhinney \& Annett, 1996; Scruggs and Brigham, 1991; Reid et al., 2017). These heightened brain processes have been found to be particularly well suited in enhancing learning capabilities in academic settings. However, there is a significant gap in the literature about how musical mnemonics engage with live entertainment, such as musicals, to create dynamic cognitive experiences, as well as the true potential of its efficacious application in learning environments (i.e., modulated history instruction in schools supplemented by arts-based field trips).

One of the defining cultural phenomena of the decade is the ground-breaking hip-hop and rap historical musical Hamilton: An American Musical (2015) by Lin-Manuel Miranda. It tells a reimagined and modernized tale of $18^{\text {th }}$-centry revolutionary America and its founders as they try to shape the future of their country post-independence from Britain. Most uniquely though, it transforms the often stereotypically stuffy and distanced history of the founding of the U.S. into a modern, entertaining, and relatable narrative. But this hip-hop musical was not the first production to combine musical genres to such unique effect. Ten years prior to Hamilton, Miranda had written another musical, In the Heights (2005), which was a multi-genre Caribbean influenced rap musical and was a stunning success. However, In the Heights was an incredibly localized narrative about a small neighbourhood in NYC. Hamilton, on the other hand, would grip audiences in the U.S. (and, later, in several other countries) with a story they were already familiar with: the founding of the United States. 
Miranda stumbled across the story of Alexander Hamilton rather surreptitiously at an airport kiosk where he spied the biography, Alexander Hamilton, by Ron Chernow (Horwitz, 2016). Reading about Hamilton's life fundamentally moved Miranda as the young musical writer connected with the deeply personal narrative that Chernow had presented (Horwitz, 2016). As a fellow Caribbean native, Miranda felt that Hamilton's story reached through centuries to map onto his own experiences, and that audiences needed to hear Chernow's version of the story. Even from the first read, Miranda envisioned this story as a hip-hop show (Horwitz, 2016). Miranda grew up in Washington Heights (a small neighbourhood in the uppermost part of NYC) in the 1990s - an era in which The Notorious B.I.G., 2Pac, Nas and other artists helped to popularize rap and hiphop (Horwitz, 2016). These artists thus became central to Miranda's musical canon and a part of his musical identity and personal history (Horwitz, 2016). From Miranda's perspective, there was no better way of telling the story of past Americans to present Americans than in the language of modern music. Over the next seven years, work on the production of Hamilton began. While Miranda initially intended it to be a concept album, it quickly morphed into a blockbuster Broadway musical.

Miranda first performed a part of Hamilton ("Alexander Hamilton") for the Obama administration in 2009 (six years before opening night), more as a spoken word experiment than the song it would turn into (Horwitz, 2016). However, that performance went viral on YouTube and other social media platforms and with the expressed enthusiasm for the unique story of Alexander Hamilton, Miranda devoted himself to creating the musical. That night, Miranda demonstrated that Alexander Hamilton, Aaron Burr, and George Washington could be more than just historical figures; they could be relatable characters with ambitions, hopes, and dreams much like the audience's own. This has always very much been the central point of Hamilton, as Miranda 
himself is credited saying: "by writing about Hamilton you're really writing about America today" (Miranda \& McCarter, 2016, pg. 174). The musical became known as a profound narrative about the founding of America which connected audiences with this historical period in innovative ways so as to make history "cool" again for generations of American youth and adults. Miranda crafted a technical "masterclass" of a musical with intelligent, minutely crafted songs, lyrics, and themes to help audiences identify with the characters, their emotions, and ultimately render the historical content more memorable. In this project, I explore the functions and utility of musical mnemonics as one of the key elements that underpinned the success and impact of Hamilton.

What is it about Hamilton that after even just one viewing leaves an audience with a greater understanding of historical events than reading a history textbook on the same topic? Of course, key to the success of Hamilton are its many "earworms," or songs crafted around short, appealing and memorable tunes to facilitate retention and recall. Additionally, Hamilton conveys carefully condensed information in a short span of time, aided by the fast tempo of hip-hop and rap, while utilizing core concepts of music theory, psychomusicology, and the emotional core of music. Hamilton differs from many other musicals in terms of the sheer amount of historical material it conveys to the audience and in the way that it connects audiences of all ages through relatable, modern-feeling historical narratives. But which specific techniques does Miranda use to accomplish this in Hamilton and what can be learned from these techniques to modify current curriculum and teaching approaches?

To establish the pedagogical merit of musical mnemonics in Hamilton, it is important o first identify their educational benefits as noted in traditional learning environments. Scholarly research into the incorporation of musical mnemonics into modern teaching approaches has noted numerous studies where students saw significant benefits from incorporating musical learning into their 
education through activities such as arts-based field trips. Positive improvements included boosts in mental health, recall, retention, grades, emotional development, socialization skills, and more (Skala, 2018; Garrido et al., 2016; Greene et al., 2015; Green et al., 2018; Pogue, 2021; Goldstein \& Winner, 2012; Lee et al., 2015). Specifically, by introducing students to regular arts-based activities or field trips, students will be better positioned to develop an appreciation for art, culture and entertainment. Moreover, this correlates directly with Pierre Bourdieu's idea of cultural capital (which will be discussed later in the paper), who believes that disadvantaged families are unable to fully engage with high culture due to economic or social barriers and thus see less development in key areas (Kisida, 2015).

Using Hamilton as a case study, this paper analyzes the efficacy of musical information processing (i.e., musical mnemonics) in musical theatre through elements of music theory (such as chord progression, key, tone, etc.), form-specific narrative or genre conventions and emotional evocation, and how the chosen musical style is a mnemonical vehicle to explore hip-hop culture, identity, and history. This study will suggest that the incorporation of arts-based field trips for viewing live entertainment such as Hamilton as a modification of current history instruction has the capacity to enhance learning and critical thinking and, most importantly, to promote a more relatable understanding of history. 


\section{LITERATURE REVIEW}

The study of musical mnemonics has been influenced by a variety of different disciplines including neurology, musicology, cognitive psychology, neurochemistry, and pedagogy. At the intersection of music theory, neuroscience and psychology, musical mnemonics attempts to understand how music influences human brain processes. One of the core human cognitive processes is memory: the ability to store and later retrieve information. Memory is a crucial brain process but it declines naturally as humans age. However, studies have found that music can act as an essential mnemonic device for absorbing new information, retention, and recall, especially in aging adults (Deason, 2018).

Some of the earliest studies on the effects of music on memory and information recall were conducted in the 1980s. While at the time limited significant differences were observed between recall ability with music accompaniment versus spoken passages, initial data was able to demonstrate improved memory within a music setting over a longer period of time (Gingold \& Abravanel, 1987). Theories developed since then have established the ability of music and melody to act as mnemonic devices for better retention, particularly when information is coded into musical lyrics (Rainey \& Larsen, 2002; Chazin \& Neuschatz, 1990). Not only has research found music to be an effective mnemonic device, but musical accompaniment or the incorporation of music in information processing itself is also able to increase recall and the chunking of words, as the abovementioned children's song for learning the alphabet demonstrates (McElhinney \& Annett, 1996; Scruggs and Brigham, 1991; Reid et al., 2017).

To explore the neurochemical influence of music, researchers have developed case studies focused on studying musicians, due to their continued and prolonged exposure to formal mechanisms of music training. In this vein, several studies have discovered that artistic 
individuals within the music or theatre fields are more likely to undergo cognitive enhancements (i.e., increased memory or processing speed) due to their years of exposure to music or theatre training (Groussard et al., 2020; Williamon \& Valentine, 2002; Okada \& Slevc, 2018; Moreno et al., 2008; Moreno et al., 2011). Further, through electroencephalogram (EEG) testing, it has been found that different parts of the brain are actually stimulated through musical learning and that "verbal learning with a musical template strengthens coherent oscillations in frontal cortical networks involved in verbal encoding" (Peterson \& Thaut, 2007, p. 1). Such strengthening in neuroactivity through music is a core part of many music-based therapies for neurodegenerative diseases such as Alzheimer's or dementia, which demonstrates that musical encoding plays a crucial part in episodic memory (specific personal experience-based memories) and recall (Simmons-Stern et al., 2012; Simmons-Stern et al., 2020; Ratovohery et al., 2018; Moore at al., 2008; Hess \& Bradley 2020). For example, Ratovohery et al. (2018) found that when compared to young adults, older adults suffering from a general comparative decline in encoding and information retrieval were able to remember sung lyrics better than spoken lyrics both immediately and ten minutes later.

The study of musical mnemonics holds tremendous value for the advancement of modern pedagogy. Numerous studies have noted the positive influence of musical mnemonics for information retention in classroom settings, boosting not only memorization but also comprehension (Ostendorf et al., 2020; Hussein \& Jakubec, 2014; Dresler et al., 2017 Scruggs \& Mastropieri, 2000; Isabel, 2015; Harman \& Rule, 2006). It also appears that musical mnemonics have been particularly effective for students with learning disabilities, due to the challenges they encounter with incorporating semantic memory. For example, in a study that included over 60 students with learning disabilities, the research subjects were asked to memorize reasons for 
dinosaur extinction and were more successful with their recall when the information was presented to them with an appropriate musical reference (Scruggs and Mastropieri, 1990; Mastropieri et al., 1987).

While musical mnemonics have been thoroughly explored in the realms of pedagogy and neuroscience, there is much research left to be conducted on its use in popular entertainment such as films or musical theatre. Future research will be able to delve into the intricate brain processes that captivate an audience's attention through live and or multimodal entertainment which may leave lasting and more vibrant memories than spoken or written communication. As well, it is important to consider how experiences generated by historical musicals such as Hamilton might be more effective methods of teaching history due to musical and stylistic modernization through genres like hip-hop and rap.

As discussed above, a core aspect of psychomusicology and thus musical mnemonics is that specific features and conventions of music are able to trigger certain reactions in our brains, particularly through emotional impact. It is this triggering of emotional effect that heightens a musical experience, increasing enjoyment, intensifying mood, and enhancing memorability. This idea of music triggering emotions has been one of the leading points of academic interest for researchers in musical brain stimulation since the 1930s (Eerola et al., 2013). The goal of such research is to identify exactly which core musical cues are responsible for communicating emotion, as well as why the human brain encodes them as such. Prominent researchers in the field of psychomusiciology, such as Gabrielsson and Lindström (2010), identify some of these musical components to include "mode, tempo, dynamics, articulation, timbre, and phrasing," to name but a few (Eerola et al., 2013, pg. 1). Emotions, ranging from happiness, sadness, anger, or even serenity are negotiated through various combinations of these musical cues. For example, it is a 
common perception coupled with proof from empirical studies that a faster tempo or higher pitch indicates happiness largely due to its similarity to human speech patterns as excited people speak more rapidly (Eerola et al., 2013). Specific tempos in musical theatre are then often directly connected to specific characters, where, for example, a faster tempo might be strongly associated with ambition, whereas a slower tempo might be associated with laxness or laziness (Bell \& Chicurel, 2008). Pitch, on the other hand, refers to the specific frequency of a certain musical note which is most commonly understood as A, B, C, D, E, F, G, or Do, Re, Mi, Fa, Sol, La, Ti (Tsekoura \& Foka, 2020). When notes go up or down in pitch (also known as frequency) this is referred to as a scale, with the most common scale (chromatic) negotiating semitone (half) steps (Tsekoura \& Foka, 2020). Research like Tsekoura and Foka (2020) has discovered through EEG signals that the brain is able to correctly identify tones with an accuracy of up to $70 \%$. This neural connection points to a certain degree of musical priming that enables humans to interact, process, and recall music on a more complex level, even subconsciously. Other positively associated musical cues include melodic direction (i.e., if the notes are going up versus down), which often works to evoke a feeling of uplifting or improvement (Gomez \& Danuser, 2007). Paired with modality (i.e. if the piece is in a major or minor scale), this further augments the emotional processing of a certain melody or piece (Schutz, 2017). A major scale is more strongly associated with positive or bright feelings whereas a minor scale has negative or sadder connotations (Bell \& Chicurel, 2008). This association in pitch is drawn from human emotional speech, which audiences use as a basis to interpret a given piece (Schutz, 2017). Humans tend to speak in higher tones when excited or happier (imagine talking to a baby or praising a puppy) and thus musical audiences respond in similar ways to musical traits that trigger such personal reference points. While there are centuries of music theory fundamentals that form the basis of musical analysis for 
psychomusicologists, several more transient factors can also influence the perception of music. For example, triggers such as personal experiences, context, and listening environments can greatly influence one's emotional interpretation of a given piece (Gomez \& Danuser, 2007). Imagine, for example, the electricity of watching a concert live in a stadium packed with screaming fans versus enjoying the same album, alone in your room. Or consider one's opinion of a song when you hear it as holding music over a phone or elevator music. It would certainly be a different experience if you sought out the music on its own where it serves a greater, non-liminal purpose.

To better understand how aspects of music can influence emotion, understanding human processing of sound or noise is a good starting point. When notes are in a particularly high register $(1,510 \mathrm{~Hz}$ or higher), music scientists have discovered that these notes are interpreted as unstable or tense in comparison to lower register notes (Juslin \& Sloboda, 2010). A famous example of the extreme high register is the shrieking string notes commonly found in horror movies to create tension. Due to the biology underlying hearing, the body can only tolerate tones within a certain frequency before they physically cause pain or discomfort. That is why, for example, machinists wear protective earmuffs to block out the high-pitched grinding of machines. The body thus reacts naturally to music that is closely related to previous experiences of danger or unpleasantness, forming an emotional interpretation baseline.

As previously mentioned, direction or movement in music is necessary in order to differentiate between sounds and true music. Intervals are the gaps or steps between two different notes in a certain piece or phrase. In other words, they are one of the building blocks of musical theory. Afterall, the separation between sound and music is simply a progression or sequence of sounds (Taylor, 1982). The composition of intervals is just as important as their sequence. A collection of notes (much like how a combination of words can create a sentence) forms a scale (Juslin \& 
Sloboda, 2010). One of the major technical differences between a major and a minor chord is the half step down of the third note to a minor position, which is thought to resemble the tone and pitch of sad human speech and thus evokes similar feelings (Juslin \& Sloboda, 2010). When pitches are combined in phrases or melodies, audiences' brains react by processing the pitches into their own thoughts, typically via images, ideas, or feelings (Taylor, 1982). But, the true challenge of impactful music is to leave an impression. According to Massro (1970), the sensory images produced while listening to music are usually stored in the preperceptual memory, a process which typically only lasts for a quarter of a second. Therefore, for longer lasting musical memories, it is important to connect a musical moment to a part of the brain intended for longer term storage, such as past experiences (Taylor, 1982). This long-term storage facility for memories is also known as episodic memory, which functions through the recall of personal past experiences (Taylor, 1982). When a memory finds a long-term place in an audience's brain (typically the left hemisphere for emotion recognition), this connection is bridged through something known as an iconic relationship (Gomez \& Danuser, 2007; Pralus et al., 2020). An iconic relationship bridges some part of musical structure and a non-musical event, memory or agent (Gomez \& Danuser, 2007). For example, the listeners might recall the fast tempo of high energy events, such as a sporting event or an emergency which have accelerated speaking or hectic movements, and thus bridge an emotional reaction to fast tempo music (Gomez \& Danuser, 2007).

Some musicologists believe that the evocation of emotion in music happens in two stages: 1) the triggering of an association between a musical cue and a specific emotion, much like how one might associate the colour blue with sadness and 2) contagious evocation, which means the triggering of a certain emotion because of one's environment (Hunter et al., 2010). Contagious evocation is largely at play in the public or communal reception of music where each individual is 
able to play off the emotional reactions of those around them. This is one of the reasons live entertainment in musical theatre is particularly effective for generating emotional responses.

Music processing in the brain is a highly complex procedure that activates various brain regions. From a neuroscience perspective, the emotional processing of music actually occurs in both brain hemispheres, but each hemisphere carries out different parts of the process; the right hemisphere is in charge of experiencing the emotion whereas the left hemisphere is in charge of recognizing the emotion (Pralus et al., 2020). Thus, from a neuroscience point of view, the brain is quite actively involved in musical processing. Since this process involves recognizing emotional experiences, it is not surprising that there is an overlap between emotional processing and another key function of the human brain: the collecting, processing, and revisiting of the past through memory (episodic memory) (Hayes et al., 2018).

To understand episodic memory and how it interacts with other memory related brain processes, one needs to understand the axes on which human memory systems function. These axes are what separate different forms of memory processing, as well as where they are stored in the brain. On one axis, there is declarative versus procedural memory (Hayes et al., 2018). Declarative refers to specific items or facts that are very explicit or conscious in recollection, for example the fact that the U.S. Declaration of Independence was signed in 1776 (Hayes et al., 2018). Procedural, on the other hand, is more implicit and unconscious, such as tying shoelaces or riding a bike (Hayes et al., 2018). The other axis involves short term versus long term memory. For example, episodic memory exists as a declarative, long-term memory system (Hayes et al., 2018). What differentiates episodic memory then from semantic memory (general recollection) is the element of personal experience (Hayes et al., 2018). Episodic memories are the re-living of one's past experiences and emotions within certain spatiotemporal constrictions (Hayes et al., 2018). 
When humans recall an event, it is not just how that event unfolded but also what that event meant emotionally (Hayes et al., 2018).

It is thus clear that the interplay between episodic memory and music is what triggers the formation of emotional, personal connections to sound. This is perhaps why individuals suffering from neurological disorders such as Alzheimer's disease or dementia, who are often characterized by impairment specifically to episodic memory, are commonly prescribed music therapy to retrigger more defunct brain processes (Davies et al., 2004). Moreover, music therapy is an established practice for treating patients with limited brain functions, cognitive impairments, trauma victims, individuals with learning disabilities, and so on. While human memory is deeply personal and thus often used to trigger other human memory processes, such as semantic memory, it also possesses the unique ability for symbolic and abstract understanding of language, concepts, ideas, etc. and allows for more creative manipulation or comprehension of ideas (Binder \& Desai, 2011). In effect then, the literature reviewed thus far suggests that music can trigger enhanced brain functionality.

But how does the brain create a bridge between a past memory and a present sensory experience? One of the means by which this can happen is music. In psychology, this idea of heightening conceptual knowledge through comparison or support via sensory or motor simulation related to that concept is known as embodied cognition (Binder \& Desai, 2011). In embodied cognition, emotion is a particularly strong factor in colouring experiences of words or concepts to lend meaning (Binder \& Desai, 2011). Humans instinctively encode their memories with a dominant emotion that represents that experience. This is why, for example, humans often look back so fondly on their childhood which they encode with care-free happiness. Music, due to previously mentioned cues or traits, is able to evoke similar feelings in audiences. Thus, when 
audiences are exposed to a certain musical emotion, their brain processes the experience by calling forth something the individual already knows and understands — a past memory encoded with that same emotion. Different musical cues are thus different techniques to trigger memories and connect with audiences in a meaningful way, often in order to convey certain messages or ideas, particularly in musical theatre. One such example is harmony, the relationship or system between two or more simultaneous notes. This is a valuable tool for emotional processing in music as it reinforces certain emotions based on its connection to certain scales (i.e. major vs. minor) (Bell \& Chicurel, 2008). Other technical aspects of music that trigger specific emotional expressions include articulation (the way notes are performed), such as sharp and plucky (staccato) which invokes giddiness, energy or intensity, versus smooth and flowing (legato) which might intimate a tenderness or longing (Bell \& Chicurel, 2008).

It is not just the structures and conventions of music that elicit certain responses from audiences; the context of the musical experience is key to this process as well. According to the Cue-Redundancy Model, emotion is conveyed in music due to a variety of psychoacoustic cues which are negotiated through both universal and cultural lenses (Susino \& Schubert, 2018). The more familiar one is with a certain piece, genre, or style of music, the more likely it is that one will use such a piece as a cultural reference point for future listening experiences (Susino \& Schubert, 2018). For example, the North American style of rap has very different thematic associations than for example Eastern European Folk music and thus each genre has different associations for different audiences. Therefore, due to the vast differences in music found around the world, responses to cues can vary dramatically (Susino \& Schubert, 2018). The two genres most relevant for an analysis of Hamilton are hip-hop and rap. The Encyclopedia Britannica defines hip-hop as “a cultural movement that attained widespread popularity in the 1980s and '90s; also, the backing 
music for rap, the musical style incorporating rhythmic and/or rhyming speech that became the movement's most lasting and influential art form" (Light \& Tate, 2021). Its key musical features include beats typically made from electronic instruments or samples of other songs, as well as lyrics in the style of rapping (Light \& Tate, 2021). Because its history is intertwined with that of lower-income African Americans in the U.S., associations with the genre (at least from the outside) typically interpret the genre as lying outside of the mainstream and thus as a more inherently "deviant" musical taste to have (Light \& Tate, 2021). Rap, on the other hand, is defined as a "musical style in which rhythmic and/or rhyming speech is chanted ("rapped") to musical accompaniment" (Britannica, 2020). Rap is connected with hip-hop not only because the two are often combined in musical practice but also due to their cultural associations with the African American community and their struggle against oppression. Furthermore, in the 1980s a new form of rap emerged known as "gangster rap" which focused much more on the sexist, violent, and taboo topics that modern audiences might associate with the genre (Britannica, 2020). Moreover, the use of hip-hop and rap by African Americans and other minority groups as a medium for protest and advocacy has shaped modern understanding of the two genres.

Genres such as hip-hop and rap are communicated in part through musical cues, which can generally be organized into one of two categories: sensory/acoustic or cognitive (Barrett \& Janata, 2016). Acoustic cues refer to previously mentioned musical traits such as timbre or pitch whereas cognitive cues refer more to the relationships between musical events in tonal space or time and are typically expressed musically through rhythm or meter (Barrett \& Janata, 2016). Some examples of universal cues include tempo and timbre. As previously mentioned, an increased tempo is typically viewed as more upbeat and happier (Susino \& Schubert, 2018). Extra-musical or culture-specific cues, on the other hand, could refer to things such as genre labelling (Susino \& 
Schubert, 2018). In other words, Susino \& Schubert (2018) found that they were able to stimulate certain emotional reactions to music by simply labeling the genre of the music that they played to participants — in other words, the label primed the audience (Susino \& Schubert, 2018). This would provide evidence for the belief that "emotion in music is partly dependent on previously held, culturally bound beliefs" (Susino \& Schubert, 2018, pg. 17). For example, negative stereotypes are often held against North American rap due to prejudice against African Americans and lower-class groups. On the other hand, classical music is often registered as more elegant or lofty as it was historically the music of privileged groups.

Previous studies also provide a basis for considering how musical experience can enhance learning in educational contexts. Scholarly research has evaluated the impact of multimodal (i.e., musical) learning experiences or environments, namely the incorporation of arts-based field trips to attend events such as live plays or musicals. Researchers like Pogue (2021), Goldstein and Winner (2020) and Lee et al. (2015) noted marked positive improvements in students who attended such events versus those less exposed. These benefits included increased interest in cultural capital, improved critical thinking stills, more developed musical tolerance, heightened recall and retention of information, higher grades in school, improved attendance records, and more.

The above literature review has identified the key traits and processes found within music such as genre, listening environment or context, music theory elements, brain processes capacity, and musical cues to name a few which are taking active part in creating a beneficial musical learning environment. The next section provides an overview of how these concepts inform my analysis of Hamilton. 


\section{METHODOLOGY}

I take a three-pronged approach to analyze the use of musical mnemonics in the hip-hop musical Hamilton to create an engaging multimodal learning experience. My study is guided by the following research questions:

1) In the current scholarly body of literature on music and memory, which musical elements are associated with mnemonic functions?

2) How does the musical Hamilton use musical mnemonics, and how effectively do these elements work as narrative and pedological tools?

3) How can Hamilton demonstrate the merits of further integrating music-based learning and arts-based field trips into curriculum?

RQ 1 was addressed in the literature review, where I identified core principles of music theory prevalent in musical theatre compositions which stimulate brain processes in the form of mnemonics to ultimately enhance memory, recall, and retention. Examples of relevant musical conventions include rhythm, tempo, musical structure, key, pitch, movement, and more. This exploration enables me to pinpoint why music, over other forms of information transmission such as non-lyrical speaking or reading, is able to achieve heightened brain stimulation. The key concepts which inform my analysis of Hamilton are listed at the end of the Methodology section. The analysis of Hamilton will provide a detailed look at a few core songs from the musical to point out recurring musical features.

To address RQ 2, I identify several conventions of the musical theatre genre that work to heighten the mnemonic and pedological experiences. This includes, but is not limited to leitmotif, character songs, Act I conclusion songs, and more. In the analysis, I argue that the 
songs in Hamilton are crafted to not only reflect the narrative and historical information through its lyrics, but to also impart key aspects of characters, emotions, and the plot through musical choices. A good example of this would be the use of contrasting character songs for Alexander Hamilton ("My Shot") versus Aaron Burr ("Wait for It"), the juxtaposition of which clearly communicates their rivalry. This analysis will serve as a basis for the subsequent discussion about how the musical transmission of information can be more effective than other alternatives for learning or improving teaching when presented in a multimodal or combined format. As well, by analyzing genre specific rap and hip-hop conventions utilized in the musical, I take a critical look at how Miranda teaches about the cultural history and identity of rap (and hip-hop) music through his musical. Further, I discuss how Hamilton works as a commentary on historical narratives, historiography and who really writes history. This commentary will demonstrate that Hamilton is able to provide a meta education on the field of history and provoke critical thinking about the field of history and the act of writing it.

Finally, in regard to RQ 3, I explore the merits of including arts-based field trips in the modern curriculum which would point towards the positive impact of musicals like Hamilton. This will work to show that schools can greatly influence the progress of their students through the integration of music into their learning environments. Thus, this will serve as concluding evidence of the mnemonic value of music and its ability to create engaging learning experiences, with Hamilton as but one example.

My discussion and analysis of Hamilton uses core concepts within music theory, neuroscience, emotional communication, and psychomusicology. Naturally within the constraints of this paper, it is not possible to provide an in-depth explanation of each concept or theme and it may be challenging for readers without a background in music theory and related 
fields to recognize the links between each of these key ideas. The following concept map, which includes the categories of concepts used in the analysis, is designed to aid readers in following my discussion:

1) Experiential music associations

2) Musical theatre conventions

3) Rap narratives

4) Leitmotif

5) Repetition

6) Genre

7) Music theory

8) Narrative techniques

9) Hip-hop and rap culture

10) Historical discourse/historiography 


\section{ANALYSIS}

\section{Experiential Music Associations}

As previously discussed in the literature review, an audience's genre preferences, cultural background, mood and ethnicity play integral parts in how one encodes and interprets music. Music is not listened to or processed in a vacuum isolated in time. Each listener brings with them their own emotions, experiences, background, etc. to the music, unpacking it uniquely from others who could be listening at the same time. Ultimately though, the strongest emotional interpretation of music comes from an audience's ability to personalize some aspect of the music they are listening to. For example, many people can envision a vivid memory of their past when listening to a specific song. This fond reminiscing of a time past is nostalgia, which is a particularly strong emotion that has fueled creative thinkers for centuries. The strength of nostalgia in music stems from its utility of emotional communication. As nostalgia fuels the yearning to return to one's past, music can latch onto those memories and feelings. However, while nostalgia is typically formulated around a fond memory, there is typically a degree of sadness to the sentimentality as one recognizes its fleeting nature. Thus, it is then natural that, historically, feelings of nostalgia are more often rooted in music with the previously discussed "sad" traits (Barrett \& Janata, 2016). Similarly, these "sad" musical cues (i.e. slower tempo, lower tonal range, etc.) are also often associated with being pensive or melancholic. Such a nostalgic musical experience is then further strengthened the more familiar one is with the piece itself, its structural or cultural connections, or any personal autobiographical connections that a listener could form (Barrett \& Janata, 2016). These initial feelings are then expounded upon by the specific lyrics and thematic content of the song. For example, in Hamilton, "Burn" not only strikes an emotional chord due to the remorseful feel of the music or raw emotion that Eliza Schuyler's actress, Phillipa Soo, brings to the 
performance, but also the context of the situation; a hurt wife who feels betrayed by the man she fell utterly in love with. That is certainly a feeling that audiences around the world can understand or even relate to. As well, the entire narrative around a post-independence America struggling to detach itself from its colonial past to forge a new identity functions on the principles of nostalgia. By encoding this transition period of America much like someone who would fondly remember their 20s or 30s, the music in Hamilton becomes more relatable.

\section{Educative Musical Theatre Conventions}

The above literature review established a clear and rich theoretical basis for the psychological and emotional effects of music on audiences, based on specific cues or traits. For this case study of Hamilton, I pick out these musical techniques and explore what they seek to evoke in audiences and in what manner. While many audience members might not understand the theoretical implications of certain chord progressions, cadences, or key signatures, their brains still have those natural reactions and brain processes to the music. Hamilton cleverly uses style, genre, and form conventions to deliver a unique multimodal learning experience to pay homage to music that is familiar to the audience while simultaneously subverting audience expectations and generating more exciting experiences. The use of these techniques creates a more compelling narrative for a historical experience that is far more relevant and memorable than conventional teaching methods.

Hamilton opens with the titular song, "Alexander Hamilton," in which the entire main cast and ensemble are on stage as the musical's narrator, Aaron Burr, introduces the audience to the main players to set the stage for the protagonist, Alexander Hamilton (Miranda \& McCarter, 2016). This helps the audience clearly identify early in the musical who the plot will revolve around and who one should probably be paying the closest attention to. The opening song, in a 
sense then, functions much like a dramatis personae (a list of the main characters of a play, novel, or narrative). Effectively then, the song "Alexander Hamilton" also provides the audience with an introduction to the major historical figures in play beyond just their names. Presenting Burr as the main narrator instead of the protagonist in Hamilton is an interesting and deliberate creative choice; this is one of the ways Miranda develops the theme of historical narrative and how history is largely shaped by those who tell it (Shrader, 2019). Thus, knowing that Burr becomes Hamilton's primary rival and is eventually driven to kill him, the audience soon realizes that Burr can provide an alternative perspective, and much more critical one, than Hamilton (Shrader, 2019). I would posit that this narrative choice is also effective in provoking critical thought about the field of historical study itself as the musical would have been a drastically different one if narrated by Hamilton.

Next, another hallmark of musical theatre is the "I Want" song. These pieces are found at the front end of the show and are typically focused solely on one of the characters who addresses the audience to reveal their goals and motivations (Miranda \& McCarter, 2016). Hamilton's “I Want" song is "My Shot" where he talks about the risks and chances that he is willing to take to make a new life for himself in New York City. This is contrasted well with Burr's "I Want" Song, "Wait for It", where he, in contrast to Hamilton, expounds on his desire to play his cards close to his chest and proceed through life cautiously (Miranda \& McCarter, 2016). I believe that this is an effective tool for understanding Burr and Hamilton's historical relationships; the contrasting "I Want" songs instantly create a tension and dynamism between the two main characters. Moreover, to show how Burr and Hamilton are ideologically opposed, each character is ascribed a unique musical style so that, musically, they are opposed as well. For example, Hamilton's chosen genre of rap holds with it the historical connotations of African American 
culture which originally used the genre to give a voice to the disenfranchised. Burr, on the other hand, rarely raps in the musical as his character believes one must wait calmly for the right opportunity, as is reflected by the smoother melodies of the jazz genre - a musical form modern audiences would associate with the laid-back atmosphere of jazz clubs or elevator music. Typically, in musicals it is only the protagonist who is granted an "I Want" song, so by providing one for Burr, an intense rivalry where the two are literally fighting for the spotlight is better illustrated (Shrader, 2019).

A further example of how music in Hamilton is able to effectively convey the nature of a relationship between two characters through different musical genres can be seen in Eliza Schuyler and Alexander Hamilton's relationship. Eliza's songs and stylings are much more reminiscent of modern pop stars, whereas Hamilton maintains his rapid-fire rap (Miranda \& McCarter, 2016). This, in fact, is a reference to the hip-hop genre's tradition of featuring pop singers on their albums (Miranda \& McCarter, 2016). I would argue that this contrast truly drives home the point of the married couple's differing personalities (perhaps even foreshadowing their marital issues) and eventually how Eliza will feel as though she is secondary — nothing more than a feature on the B side, so to speak ("Burn"). It is through the opposition and clear distinction of music styles in Hamilton that audiences can musically distinguish between and relate to characters in the musical. Hamilton uses musical elements to enable audiences to quickly gain an understanding of the narrative, characters, and how they interact or relate to another one.

\section{Crafting a Memorable Narrative through Rap}

In the course of a few numbers, Hamilton takes on the clear building blocks of a narrative and the audience can settle in for the dramatic retelling of America's revolutionary past. The 
success of Hamilton is all the more significant given the more recent declining interest in studying history and other humanities (Lewin, 2013). For young people wanting to move forward with their lives, it can often be hard to see the value in looking back, especially when these people and events seem so very different from their own lives. As well, the content covered in history classes can span decades, if not centuries, in just one short semester - a breakneck pace that often causes important information to get lost or forgotten. Hamilton uses music as vehicle for retention and recall, as many musicals before it, but does so in a way that demonstrates how musical mnemonics can help audiences engage with and retain dense historical material.

One of the easiest ways to enhance musical memory is to create memorable lines through predictability or patterns. In rap, this is accomplished through adherence to a specific meter and rhyming scheme. As well, one can easily enhance the novelty of a specific line by adding aspects of prose or lyricism to it. This drive towards poetry (which is often considered the true measure of skilled rap) elevates otherwise dry historical text to the memorability of an earworm. One of the most common applications of this idea in Hamilton is Miranda's complex, polysyllabic rhymes that give the musical's pieces their drive, wit, and engaging storytelling. The full utility of polysyllabic rhymes will be explored in a later section on hip-hop and rap as this technique is a key feature of those genres.

Internal rhymes are also a consistent feature of Miranda's lyrics, which are crafted to layer sounds on top of one another in order to turn an ordinary sentence into a more interesting statement. It is the evocation of prosody that will help lyrics stick in an audience's mind over a simple, spoken phrase. One example that stands out for me is Hercules Mulligan's line in "Aaron Burr, Sir": "It's hard to have intercourse of four sets of corsets" (Miranda, 2015, 2:04). In this 
case, it is easy enough to pick out the repeated "or" sounds in "intercourse", "four", and "corsets". The prosaic nature of this line is further driven home by its repetition, which is a wellestablished vehicle for memorization. Another example of internal rhyme can be found in "Schuyler Sisters" in the following line: "History is happening in Manhattan and we just happen to be in the greatest city in world!" (Miranda, 2015, 2:05). The pursuit for the perfect rhymes seems to be absolute, as Miranda himself even admits to inserting every possible rhyme for the word "Burr" into the musical (i.e. "sir", "Mercer", "bursar", etc.) just as a way to solidify Hamilton's antagonist in the audience's mind (Miranda \& McCarter, 2016). What makes the internal rhymes particularly compelling is the use of assonance or the repetition of similar sounds which can often sound more musical. Take, for example, the following two lines from "A Winter's Ball”: "Yo, if you can marry a sister, you're rich, son / Is it a question of if, Burr, or which one?" (Miranda, 2015, 0:56). Here you can see how "rich, son" and "which one”, as well as "sister" and "if, Burr" combine with repeated sounds. The lines have clear flow and direction and will be more memorable than a corresponding line in a history book.

Alongside the internal rhymes, Miranda also employs more traditional rhyming patterns such as simple couplets which help keep the content neat and clean. As well, couplets are a wellestablished practice in theatre thanks to the likes of Shakespeare and thus a poetic feature that audiences would most likely be familiar with. Examples of couplet rhymes can be found in "Wait For it": "My grandfather was a fire and brimstone preacher / But these are things that the homilies and hymns won't teach ya" (Miranda, 2015, 0:51), as well as in "We Know": "I never spent a cent that wasn't mine / You sent the dogs after my scent, that's fine" (Miranda, 2015, 1:38) Couplets, also known as end rhymes, can either be perfect (identical ending of vowel sound or consonant) or imperfect (partial matching rhymes, but not perfect) (Eastwood \& 
Hinton, 2016). An example of an imperfect end rhyme from "Alexander Hamilton" can be heard in the contrasting rhymes of "squalor" and "scholar" versus "Scotman" and "dropped in" (Eastwood \& Hinton, 2016). Particularly, a heavier focus on imperfect rhymes is an evocation of traditional rap and hip-hop, alongside internal rhymes (Eastwood \& Hinton, 2016).

Rhyme is predictable and thus creates a satisfying drive for listeners who can, in part, anticipate how the song, lyrics, or musical will evolve. This creates greater buy-in for audiences so it is less likely that they will get bored or distracted by the information being presented to them. Additionally, pauses or beat rests within pieces can create further anticipation or evoke a more visceral feeling of stasis. Like a held breath, you want to know what comes next and are more likely to lean forward in your seat waiting for that. A clear example of this can be found near the end of "Wait for It" where Burr and the ensemble together sing the following lines and then wait through several bars of instrumental before Burr comes back in with the "Wait for it" line: "When so many have died / Then I'm willin' to-“ (Miranda, 2015, 2:52).

As previously mentioned, repetition is an effective way to capitalize on a good rhyme. Not only does it solidify the meanings that the lyrics might be trying to get across, but by having certain rhymes, lyrics or phrases recur throughout the musical, audiences can track character development and even be treated with some foreshadowing. For example, while "My Shot" and "Wait for It" are Hamilton and Burr's respective "I Want" songs, some of the key lyrics from the two songs are repeated throughout the musical as a way of reinforcing the idea that the two protagonists are opposites, as well as clearly identifying their personalities for the audience. This includes Hamilton's "throwing away my shot" lyric as a reference to his eternal struggle which culminates poetically in him pointing his pistol at the sky in his inevitable duel with Burr, whereas Burr stresses the idea of "talk less, smile more" to Hamilton as a contrast to the latter's 
excessive need to talk and be noticed. Ultimately, it is the technique of rhyme and repetition that enhances memory, particularly when combined with a catchy tune or melody.

\section{Strengthening Associations Through Leitmotif}

Another convention of musical theatre which focuses on repeating ideas is the leitmotif. Leitmotif is a vehicle for musical motive aimed to evoke certain emotions, impressions, or feelings as a way to produce layered meanings for the audience (Bribitzer-Stull, 2015). One definition of it categorizes it as follows: "a short, uncomplicated musical phrase or theme, usually one to three measures, which is employed, and reused, by the composer when he deems it important to the composition" (Bribitzer-Stull, 2015, pg. 8). The key term is "theme," as the leitmotif works to assign a certain musical "label" to a character, event, etc. to facilitate recall and in this way functions as a musical mnemonic (Bribitzer-Stull, 2015). For a leitmotif to be effective, the musical phrase has to be distinctive enough through various musical structures or cues and then be repeated in order to solidify it as a theme (Bribitzer-Stull, 2015).

At its core, leitmotif, like other types of musical mnemonics, also evokes meanings that are culturally associated with certain musical elements to help the audience connect with the theme (Bribitzer-Stull, 2015). The human desire to build core connections out of unfamiliar or insignificant experiences is why there are phenomena such as lucky numbers, special socks, etc. (Bribitzer-Stull, 2015). Memory evocation in music can be understood as an extension of this phenomenon; it is a way of interacting with the world through associated meanings. A listener's environment and musical expectations are also able to construct certain associations. For example, in the music world, the timbre of the French horn is often associated with something heroic or regal, as in the "Binary Sunset (Force Theme)" from Star Wars Episode IV: A New Hope (Bribitzer-Stull, 2015). Other famous leitmotifs found in popular films include the iconic 
strings from Psycho (which have become so widely known that they are now associated with the horror genre as a whole) or the opening of The Twilight Zone (Bribitzer-Stull, 2015). These leitmotifs or themes seem timeless and instantly connect listeners with a certain feeling that the original usage was attempting to convey (along with other layers of meanings that have been added to the musical element through usage and experience).

A strong example of leitmotif in Hamilton can be heard in "Story of Tonight", which recurs throughout the musical to represent Hamilton's group of friends: “Tomorrow there'll be more of us / Telling the story of tonight" (Miranda, 2015, 0:38). For example, aspects of the song make appearances in "The World Was Wide Enough" and Hamilton's last words before he is killed in his duel are "Raise a glass to freedom." Leitmotifs are also effectively used as "theme songs" for the main characters. Burr's theme, for example, consists of a characteristic chord progression originally found in his "I Want" song, "Wait For It" (Miranda \& McCarter, 2016). It is a simple I, VI, III chord progression which features thematically in other songs such as "Hurricane" (Miranda, 2015, 1:56).

Musical motifs also work to represent other characters such as Angelica and Eliza Schuyler, who the audience is introduced to through the vocalizations of their names in "Schuyler Sisters" (Miranda \& McCarter, 2016). Angelica's vocalization mimics themes found within "Satisfied" (Angelica's character song) while Eliza's mimics the theme in "Helpless" (Eliza's character song). It should be noted here that Peggy does not have her own music motif as historically she died young, and the role is double cast to also play Maria Reynolds in Act II (Miranda \& McCarter, 2016). Eliza's character song, "Helpless," is particularly poignant as it describes her feelings when she fell in love with Hamilton and later will also reflect how she feels forgotten in the greater narrative of Hamilton's life (Miranda \& McCarter, 2016). With two unique and 
distinctive songs for the two sisters, it is much easier for audiences to differentiate between them and to identify their core struggles. For example, Angelica is fiery and adversarial (perhaps a contemporary association with the competitive, battle-like stylings of hip-hop) hence her propensity to freestyle rap, whereas Eliza is gentler and more optimistic, and thus never raps. This difference in genre, as discussed previously, builds on the audience's expectations and associations of those genres to lend each character additional depth and characterization.

\section{Repetition: How to Make Information Stick}

While leitmotifs tend to focus on recurring musical ideas, phrases and ideas, the lyrics themselves also utilize repetition within Hamilton to similar effect. As previously mentioned, the line, "I'm not going to throw away my shot" is central to Hamilton's never-ending ambition, which Hamilton attempts to firmly establish in the audience's mind through its recurrence. However, another core idea for his character arises in "Right Hand Man": "Dying is easy, young man / living is harder." This line is then recycled with slight alterations later in "Cabinet Battle \#1": "Winning was easy, young man / Governing's harder." The repetition with slight change aids retention for audience members and presents a sense of natural progression as America's revolution continues.

The repetition of a core melody or song is also known as a reprise in the world of musical theatre. These musical "call backs" are often transformed into songs in their own right such as "Road to Hell (Reprise)" in Hadestown or "I'll Cover You (Reprise)" in Rent. These functional parallels show clear growth or change in a character, emotion or event from one point in the show to another. By reusing the song, the musical figuratively sends the audience back in time to remember the first time they heard the song and compare it to this current rendition. Two particularly noteworthy examples found within Hamilton are "The Story of Tonight (Reprise)" 
and "Stay Alive (Reprise)" which are both used for a greater emotional effect as the audience remembers the lighter tones of Act I. In other words, repetition of musical elements and lyrical content may help to enhance the audience's comprehension and engagement with the various layers of meaning.

\section{Using Genre to Characterize Historical Figures}

Leitmotif works to give each character a certain personality but also a unique genre or musical style that functions as an identifier in much the same way as names. By coding certain emotions, events, or characters in different genres, they are not only more easily distinguishable but trigger certain genre expectations to bridge understanding for audiences. For example, Burr's most prominent songs (i.e. "Aaron Burr, Sir" and "Wait For It") feature a very specific rhythm that is reminiscent of reggae or dancehall and are notably much more laid back and relaxed than Hamilton's fast rap (Kajikawa, 2018). This contrasts with, for example, "You'll Be Back" and the other songs where King George III comes on stage to address the audience. These numbers have a very clear classical music influence (i.e. harpsichord and a waltz sway) and feel particularly like the works of Johann Sebastian Bach (Miranda \& McCarter, 2016). I believe that this is a deliberate effort to induce audiences to call forth their own cultural associations with the genre - a reaction that would encode the style as more archaic or stuffy due to its age or “outdated” musical techniques. To make King George III's music, style, and presence feel even more out of place, his little interludes ("You'll Be Back, "What Comes Next?", and "I Know Him") are at much slower pace than the rest of the musical, averaging only between $60-80$ words

per minute (Libresco, 2015). In fact, the conflict between more classically sounding music versus the frenetic energy of hip-hop or rap serves as a stylistic representation of the military conflict between America and Britain as the historical backdrop for Hamilton. Boiling down such a vast 
military and political conflict into two contrasting musical styles helps to provide more clear-cut differences between the two countries.

As well, through King George III's musical style, Miranda is sharing the history of American versus British music by tying in references and melodic homages to the Beatles, who were largely responsible for the musical influx of Brit-pop to America in the 1960s (Nereson, 2016). This characterization of the British as stuck on "outdated" music can also been seen in "Farmer Refuted" where the character Samuel Seabury sings to the tune of a waltz (a traditionally formal tempo and very reminiscent of "Minuet in G" from Christian Petzold), while attempting to deliver news from across the ocean (Miranda \& McCarter, 2016). Instead of matching his discourse, Hamilton tears apart his argument with his modern rap, which is presented as the new language of America (Miranda \& McCarter, 2016). The dichotomy of the King's "old" singing style versus the rest of the cast's modern hip-hop and rap style cues the audience to the King's inability or unwillingness to adjust to the rapid pace of historical change and foreshadows the fact that he will be left behind as America no longer requires Britain (Truax, 2020). This is particularly obvious when one notes that the King sings in very simple end rhymes, heavily utilizes repetition, and overall has a more "simplistic" approach to singing (Miranda, 2015, Genius Lyrics). Finally, to drive home the role that King George III plays within the musical, he is also characterized in the musical's songs as a petulant "ex" who is complaining about the U.S. "breaking up" with him and moving on - a story much more relatable to a 21st-century audience (Horwitz, 2016).

Other examples of contrasting musical genres to distinguish different characters can be seen in the gospel and metronomic songs of George Washington ("History Has Its Eyes on You") versus the R\&B of the Schuyler Sisters in the same titled song (Kajikawa, 2018 \& Truax, 2020). 
Jefferson is a good example of the way the music highlights a generational gap through the collision of different musical genres. For example, his style as seen in "What Did I Miss" is influenced by more old school ragtime, funk, soul, and southern Jazz (Miranda, 2015, Genius Lyrics). Jefferson is left singing these older music genres, as opposed to the newer genres of hiphop or rap, because he has only recently come back from Paris; the fact that he seems to have missed out on the new form of musical expression associated in Hamilton with a burgeoning America implies that he is behind the times (Horwitz, 2016). Once more, Miranda provides characters with contextual depth, swagger, and memorability for audiences through the association of characters with different types of music.

\section{Chord Progression and Cadence}

In order for music to become more than sound, it needs to be organized into a collection of notes or tones. To avoid sounding monotone, music also requires direction and movement. Chord progression is one of the ways a song interfaces with its scale and this musical cue is used in Hamilton to develop characterizations. For example, when one dissects Burr's I-VI-III chord progression, it becomes clear that it has no natural home or ending (which would typically be a IV or $\mathrm{V}$ chord) thus invoking a musical sense of waiting or inconclusion, much like Burr's "Wait For It" (Kajikawa, 2018). The roman numerals assigned to chord progressions relate to how many degrees or steps in a certain scale the chord is above the root or core of the chord. For example, in C Major, the third chord would be an E minor chord because $\mathrm{E}$ is three steps from C, the root of the C Major scale. By comparing Burr's chord progression (I-VI-III ) to that of Hamilton's in "My Shot" (I-III-IV-VI-V), it is evident that Hamilton's has that natural or perfect $\mathrm{V}$ end chord with a natural lift near the centre as the chord grows from a I to a $\mathrm{V}$ - a musical 
expression of ambition or an opportunity taken (Kajikawa, 2018). Burr, on the other hand, is left inconclusively waiting.

Particularly relevant for Burr's chord progression is the idea of cadence in music, which is the conclusion of a chord progression that serves as the lasting impression for the musical phrase (Bell \& Chicurel, 2008). There are cadences that are more common in music than others, such as the authentic V-I cadence or plagal IV-I cadence. The authentic cadence consists of a tone jump from the dominant (fifth) note to the tonic (first) note of the piece's key (main scale of pitches) (Randel, 2002). The term authentic or perfect is ascribed to this type of cadence due to its natural finality or in other words satisfying conclusion to a musical movement (Randel, 2002). An equivalent conclusion in human speech would be to end a sentence properly without leaving a dangling intention or unfinished verb (Randel, 2002). The IV-I cadence, on the other hand, is a tone jump from the subdominant (fourth) note to the tonic (first) (Randel, 2002). This cadence is similar to the authentic cadence in its movement or attempted resolution to the tonic but through a smaller step (Randel, 2002). Correspondingly, it can be commonly found as an ending to hymns in Western Christian churches (Randel, 2002). The I-VI-III chord progression for Burr, then, deviates from musical expectations around conclusive notes, creating more tension as the chord naturally seeks resolution to the tonic (first note of the key) (Bell \& Chicurel, 2008). Furthermore, it is common in musical theatre to create excitement or a build in the melody with an abrupt, unexpected ascending modulation (typically a half-step) (Bell \& Chicurel, 2008). Such a modulation can be a single key, but more commonly in pop music today, it is a dramatic key change such as in Michael Jackson's "Man in the Mirror" after the "change" lyric or the final chorus of Bon Jovi’s “Livin' On a Prayer” (Bell \& Chicurel, 2008). In Hamilton, examples of such a modulation to create drive can be found in "Farmer Refuted" when Samuel Seabury 
modulates the key representatively to switch debate tactics, or in "Say No to This" when the passion of Hamilton's affair culminates in a key change from A Major to B Major at the climax of the song. As well, in "Farmer Refuted", Hamilton systematically dismantles Samuel Seabury's argument by mimicking the vowel sounds and cadences of the original lines yet altering it for his own purpose (Miranda \& McCarter, 2016). Examples of this include "heed" becoming "he'd", "rabble" becoming "unravel" or "heart" becoming "hard to listen to you" (Miranda \& McCarter, 2016). The end effect is the musical layering of two voices to demonstrate the act of disagreement. A similar layering of sounds, voices, and music is accomplished in "Right Hand Man" to create auditory dissonance to evoke the chaotic nature of the scene's events (Miranda \& McCarter, 2016).

\section{Foreshadowing}

Being a historical musical, the end point of the narrative is known to a certain extent. In addition to the well-known fact that the American Revolution successfully led to its independence from Britain, audience members could easily read up on each character to see whether they survived revolutionary America. Foreshadowing is thus perhaps the most valuable device in narratives or mediums where the audience comes in with prior knowledge. For example, in "The Story of Tonight", the song begins with Hamilton and his closest friends, Lafayette, Mulligan, and Laurens toasting to the fact that they may not survive the war: "I may not live to see our glory" (Miranda, 2015, 0:01). This foreshadows the death of John Laurens who would be killed in the Battle of the Combahee River in 1782 (Miranda \& McCarter, 2016). It is also ironic for repeat viewers, as the actor who plays John Laurens is double cast as Philip Schuyler who will also meet an untimely demise in a duel, foreshadowing his father's own death. Philip's death by duel is actually also foreshadowed in "Take a Break" when Philip and Eliza are 
playing piano together. In this practice, Philip repeats his scales with the line "sept, huit, neuf" which carries the same melody as the beginning of "Ten Duel Commandments" where Philip is eventually killed (Miranda \& McCarter, 2016). In fact, the melody from "The Story of Tonight" is also used effectively to evoke nostalgia throughout the musical, but specifically in "One Last Time" when the cast is reflecting back on their idealism before the war (Miranda \& McCarter, 2016). Due to the function of semantic memory and its efficacy in emotional processing, triggering such feelings of nostalgia is particularly effective to further Hamilton's narrative. America itself at this time was struggling to move beyond its past identity as a British colony and forge a new path for itself after the war. As well, foreshadowing is yet another technique useful for making a narrative seem predictable to create an impetus for the audience to remain engaged.

\section{Evolving Musical Technique to Emulate Progression}

Character development is a fundamental aspect of narrative as it indicates change and progression. In Hamilton, this character growth is often emulated in the musical's lyrical complexity as an indication of a character's capability. For example, while Lafayette's original rap style is more simplistic when he first meets Hamilton (e.g., in "My Shot"), he dives into a highly impressive, fast lyric spitting whirlwind in "Guns and Ships" (featuring the fastest spoken lines in the whole show) later on in the musical (Miranda \& McCarter, 2016). Lafayette's developing rap skills mirror his competency as a military officer and aid to the American Revolution with the Battle of Yorktown being his major turning point in the musical (Miranda \& McCarter, 2016). While the rapping ability and style of characters like Lafayette and Jefferson evolve through the course of the musical, Burr's does not. Instead, he is stuck repeating the same ideas and lyrics which is indicative of his desire to wait and stick to what he knows (Truax, 
2020). Miranda is cleverly drawing a clear line between musical/lyrical prowess and intelligence which may be intuitively grasped by audiences and thus requires less overt exposition.

\section{Act 1 Finale: Musical Theatre's Recap}

A final musical theatre staple that stems from the core idea of repetition is the convention of the Act I "mash-up" song, which features overlapping melody snippets and is also known as quodlibet, that is, "a [...] type of music in which well-known melodies or texts are combined in an advisedly incongruous manner" (Apel, 1944, pg. 713). This number is typically placed just before intermission in the line up to summarize the narrative of the first half of the musical and quickly highlight songs that the audience has previously heard. The quodlibet reinforces key impressions from Act I which the audience is meant to retain to aid their enjoyment and understanding of Act II when they are repeated once more. The "mash-up" or quodlibet in Hamilton is "Non-Stop" which covers 12 scenes in 6 minutes reframing key phrases, lyrics, and melodies from Act 1 songs such as "Satisfied", "Helpless", and "Wait for It" (Miranda \& McCarter, 2016). It is a final tally up of what was experienced in Act I to set the stage, quite literally, for what is to come. Other examples from famous musicals include "One Day More" from Les Miserables (1985) or "Man Up" from Book of Mormon (2011), each of which is an Act 1 send-off piece that works as the ultimate "Sparknotes" recap of the unfolding narrative. Most importantly, this Act 1 finale builds off of the central idea that for mnemonics to be effective, they must be cyclical or repeated for heightened recall and retention.

\section{Mapping Music onto Human Speech}

One of the more satisfying aspects of music, which may help to explain why people find listening to music so appealing, is that it tends to follow a pattern (Shrader, 2019). Predictability 
is not only comforting but satisfying as humans instinctively stray away from risks or surprises (Miller 1981). Thus songs, much like stories, tend to follow a clear pattern of introduction, verse, chorus, bridge, final chorus, etc. to guide listeners and to provide an overall structure for the narrative to follow (Shrader, 2019). A technical aspect of music which is highly predictable and thus very effective for creating specific reactions or emotions is directional volume modulation (also known as dynamics). The rise or fall in volume can be quickly and easily recognized. For example, a crescendo (a gradual increase in volume of music) is often used for emphasis, exclamation or for culmination, as in, for example, the music rising to a forte (loud volume) at the end of "The Room Where It Happens," signaling Burr's frustration boiling over (Shrader, 2019). Musical volume modulation mirrors patterns in human speech and communication and in the tendency of loudness to be associated with danger, anger, etc. As mentioned above, many features of music, such as meter, rhyme, chord progressions, cadences as well as prose, follow this same principle of predictability. Audiences constantly compare listening experiences to musical expectations based on their musical knowledge or foundation for evaluation purposes.

\section{The Power of Words}

But Hamilton is more than its catchy lyrics, earworm beats, or enjoyable spunk. It may also be interpreted as a discourse deliberately constructed by Miranda about the power of words through the natural prosody of music. Even back in 2015 when Miranda had only written a few songs for what he originally thought would just be a concept album, he knew he wanted to do something innovative with the story of one of America's founders. When advertising the musical originally to then-President of the United States, Barack Obama, Miranda claimed that Alexander Hamilton “embodies the word's ability to make a difference" (Miranda \& McCarter, 2016, pg. 225). This idea is particularly well developed in the middle of Act II wherein, over the course of 4 songs 
("The Adams Administration," "We Know," "Hurricane" and "The Reynolds Pamphlet"), the musical highlights the power of words and language on Hamilton's historical impact (Miranda \& McCarter, 2016). For example, the musical emphasizes, among many possible examples, that Hamilton's writing abilities won him passage to New York City from the Caribbean, that he penned dozens of foundational documents for the U.S. government, and that he captured Eliza Schuyler's heart through letters. However, "word's ability to make a difference" clearly does not always have a positive outcome, as Miranda attempts to punctuate with the Reynolds Pamphlet, a document authored by Hamilton himself explaining his own infidelity — a piece of writing that would ruin his chances for president. The song "The Reynolds Pamphlet" even holds exactly reproduced lines from the original historical document: "My real crime is an amorous connection with his wife / For a considerable time with his knowing consent" (Miranda, 2015, 0:20). While Hamilton is certainly a heavily altered and uniquely framed depiction of history for entertainment and narrative purposes, Miranda did attempt to weave in detail from the historical record. In this vein, he took history as it may be more commonly known in historical documents and turned it into something easier to digest for a modern audience.

Miranda shows that his lyrics can be so much more than just a sequence of words by weaving in many of poetry's core features to turn his words into verse, a centuries' old tradition that is able to drive the story and emotion in a far more compelling fashion for audiences (Miranda \& McCarter, 2016). He achieves this elevation through aspects like variations in rhyme or tempo, most commonly represented in music notation through the change of time signature (i.e. how many beats or pulses are in each measure or bar) which are able to evoke certain feelings or emotions. One example is in "Alexander Hamilton" during Burr's musical narration: "There would have been nothin' left to do / For someone less astute [...]" (Miranda, 2015, 2:04). To 
reflect Hamilton's frenzied attempt to get himself safely to America, the tempo of the song speeds up to match the energy. Another example can be found in "Meet Me Inside" where the regular 7/8 time signature (seven notes of equal duration per bar) which may signify chaos because of its lack of symmetry, switches down to a $4 \times 4$ time (the most common time signature) when Washington brings in order with the line "Son-“ (Miranda \& McCarter, 2016).

Miranda also creates clever musical interplay between his lyrics, style and rhythm. In "NonStop," for example, Hamilton continues to work relentlessly while his family members are trying to get him to slow down. The chaos of this scene is well-reflected in the multitude of sounds, melodies, and songs that are all competing for attention. But once Hamilton has his mind set, it is hard to talk him down. His ability to deflect other people's concerns is represented in this song when Hamilton sings Eliza's refrain as a counter argument to her and then uses a lyric and melody from Washington's song to argue with him (i.e., "They are asking me to lead") (Miranda $\&$ McCarter, 2016). Inserting different musical styles into one song is often done intentionally to create more dissonance. Particularly, in “The Reynolds Pamphlet," Angelica's part near the middle of the song is to the backing tune of "Satisfied" which, since it is so different from the rapping and rhyme of the rest of the song, encapsulates the feeling of Hamilton's world coming apart around him (Miranda \& McCarter, 2016).

\section{Bridging Emotional Reactions: Dissonance}

In music, this overlapping or meshing of unique tones or notes, often in a discordant manner, is referred to as dissonance. The theory behind dissonance stems from ancient Greek philosopher Pythagoras who established the ratio of fundamental frequencies to differentiate between consonance (a pleasant compatibility between notes) and dissonance (Dellacherie et al., 2011). Dissonance, he theorized, would be a complex ratio (relationship between tones) such as 45/32, 
whereas consonance would be simpler, such as $2 / 1$ or $3 / 2$ (Dellacherie et al., 2011). This essentially broke down enjoyable music into mathematical relationships between elements. While dissonance typically refers to pitch frequencies outside of the musical world, a similar idea exists through musical tones. Western musical practices often emphasize conforming to certain rules such as staying within a certain key (the scale of a piece), which leads deviations to stand out and create discomfort. Such a deliberate embracing of traditionally encoded "unpleasant" sounds is leveraged at the beginning of "Blow Us All Away" with plucky strings that sound "out of place" with the core melody, which indicates to the audience that tensions are rising in the wake of the Reynolds Pamphlet (Miranda \& McCarter, 2016). Researchers like Dellacherie et al. (2011) have also theorized that there is an emotional basis of dissonance versus consonance in music and have found that dissonance is able to evoke not only a more visceral and vivid response, but also a generally more negative one (Dellacherie et al., 2011). These theories are typically rooted in previously discussed positive or negative encoding of musical cues such as volume, pitch, tuning, etc. which an audience would compare to human speech. In one study, emotional encoding was particularly evident when participants with musical education and more exposure to music theory than other people reacted more strongly to the subversion of music theory expectations (Dellacherie et al., 2011). It is also commonly understood that certain ideas around consonance versus dissonance can be culturally conditioned or embodied through collective memories, experiences, or emotions, although there appears to be an innate preference for consonance versus dissonance, as has been noted in infants (Gomez \& Danuser, 2007). For some researchers, this may be traced back to the human desire for predictability and the instinctual association with some higher pitches, volumes, or frequencies as being more dangerous. As Barrett \& Janata summarize in their 2016 study: 
These parallel but interacting experiential processes should therefore lead to some degree of observed coupling between the dynamic descriptor of the stimulus and brain areas that are supporting various facets of the perceptive, mnemonic and emotional experiences that are enabled by the stimulus in the moment (Barrett \& Janata, 2016, pg. 235).

Barrett and Janata's point is that music is an effective way of building strong associative connections between a certain stimulus and a specific brain process. Specifically, this is determined and modulated by a variety of external factors such as specific auditory features (e.g., pitch, volume, etc.) to create information and evoke specific emotions.

\section{How to Subvert Expectations for Entertainment}

There are two further conventions worth noting that subvert musical expectations to evoke certain emotions: the ninth tone interval and the ensemble. For example, in "It's Quiet Uptown" there is an instance where the melody introduces the root chord (the chord that is the basis of the scale of the piece) but then augments it with the ninth tone (an interval of nine tones), effecting a desire for release as the jump in tone is just one shy of a perfect octave (eighth note jump) (Miranda \& McCarter, 2016). Next, the ensemble is a core component of Hamilton's presentation and is a remarkable presence on the cast album. Musically, the ensemble works largely towards the case of "text punctuation," namely, to repeat, stress, or highlight certain phrases, words, or melodies that audiences are supposed to perceive as particularly noteworthy (Travis, 2017). Some examples include the repetition of "Thirty-two thousand troops in New York harbor" in "Right Hand Man" or the musical backing of the ensemble of "Wait For It." In a similar vein, the ensemble also provides additional narration beyond the instances wherein Burr directly addresses the audience, such as in "Aaron Burr, Sir" with the stating of "1776, New York City," which provides a more detached narrative role (Travis, 2017). Overall then, Miranda 
has layered both an adherence to diverse musical conventions and also many elements that are characterized by the subversion of music theory and certain genre expectations to maintain attention or "keep audiences on their feet" and to challenge the predominant understandings of what music should sound like. In other words, while humans might be naturally drawn to predictability, an unexpected subversion could be even more thrilling.

\section{Rap and Hip-hop as Vehicles for Teaching American Culture}

This paper has so far focused on applications of concepts in musical theory to analyze the musical and theatrical techniques and conventions used in Hamilton to make a more memorable and exciting retelling of revolutionary America. One aspect of Hamilton that differs from many other retellings of the American Revolution is the manner in which it uses both the form and content of music to make the story more meaningful and relevant to contemporary audiences. More than a lesson in history, Hamilton can also be a lesson in how to teach, learn and appreciate a musical culture, particularly one that Miranda finds central to American identity. To do that, Miranda emulated a part of his musical upbringing and a cornerstone of modern NYC identity: hip-hop and rap. Hip-hop is arguably deeply ingrained within American culture and in the history of the African American community. Hip-hop rap emerged in the 1970s in the Bronx, which was a low-income neighborhood of New York City at that time (Hip-Hop: A Culture of Vision and Voice). With roots in the African oral tradition in West Africa, rap and hip-hop have served as a way to connect African American communities to their ancestors (Blanchard, 2015). One can also find similarities between other traditional African American music genres such as soul, R\&B, blues or jazz (Blanchard, 2015). From the beginning, rap has been a vehicle for protest and advocacy, further elevating its role for African Americans and other disenfranchised groups in America (Blanchard, 2015). Moreover, as some researchers would posit: 
Rap music is a derivative of the oral form of literature, which is man's original medium of self-expression and artistic creativity. Rap music is a highly prolific component of a popular culture which has served as a means of expressing the plight of the black man in a predominantly prejudiced white society. Rap music came as a result of the elongated measure of exposure to slavery, segregation and prejudice (Olowoyo \& Aminu, 2019, pg. 25).

Below, I examine the role of hip-hop as a key stylistic element in Hamilton as well as the manner in which Hamilton communicates aspects of hip-hop to broad audiences.

\section{Hamilton Teaches Hip-hop Culture}

By exploring some of the cultural meanings associated with hip-hop, it is possible to unravel its function in Hamilton and the statement Miranda is trying to make about the genre in his musical. Since hip-hop's emergence in the 1970s, the main tenets of this musical genre have been to use any and all available skills or resources in pursuit of something unique, as well as to play off of the great ideas of one's peers but with a personal flair (McCollum, 2019). In other words, healthy competition is what helps the genre thrive (McCollum, 2019). Competition is the core dynamic between Alexander Hamilton and Aaron Burr as both attempt to impart meaningful legacies and avoid being lost to posterity. Not only is the musical centered on the Hamilton-Burr competition, but it also tells the stories of other individuals struggling to solidify their identity in a revolutionary reality (e.g., George Washington, a nascent post-colonial America, Lafayette's loyalties outside of France, etc.) Additionally, as a way of understanding the genre, scholars have identified six core elements of hip-hop culture, all of which were to some degree integrated into Hamilton: 1) DJing, 2) MCing (rapping), 3) break dancing, 4) graffiti writing, 5) theatre/literature, and 6) knowledge of the self (McCollum, 2019). 
The culture of DJing, or the creative and artistic mixing of sounds and beats into music, revolves around the technology of the turntable, which hip-hop culture creatively reused as a sound system that combines records to create new sounds and songs (McCollum, 2019). Hamilton pays homage to the turntable through the moving centrepiece of the stage, which is a large-scale physical representation of a turntable, by inserting the characteristic turntable "scratching" sounds into several songs (e.g., the beginning of "Yorktown"), and by incorporating remixing into songs such as Angelica's "Satisfied," which is in essence a remix of her sister's previous song, "Helpless” (McCollum, 2019). These are just a few examples of constant interjections of smaller sounds or music snippets in various tracks in Hamilton that allude to the musical practices of hip-hop DJs. In fact, when Hamilton was still a concept album, it was entitled The Hamilton Mixtape. The mixtape was an important creative medium in hip-hop and rap culture produced through a combination of record scratching, sampling, and mixing tracks to create a sense of DJ presence - all of which can be found throughout the Hamilton album (Williams, 2018).

Next, MCing is the physical act of rapping poetic lyrics over a beat to create a song (McCollum, 2019). The most sought-after feature of a proficient MC is "flow," which refers to the fluidity of rhyme and rhythm in the rap performance (McCollum, 2019). Proficient MCs are expected to demonstrate increasingly more complex or innovative techniques such as freestyling, beat switching, and syncopation (off-beat rhythms), among other vocal techniques (McCollum, 2019). Alexander Hamilton appears to be modelled on the "expert MC," since he uses elevated rhymes, complex metaphors and clever wordplay and outwits his other rap "opponents". More overt references to MCing can also be found in the "Cabinet Battle" songs, where the stage is set 
up like a rap battle and the two opponents actually carry physical microphones instead of using concealed mics, which are more typical of musical theatre pieces.

Arguably, the most important element of hip-hop culture is the idea of "knowledge of self," which is integrated into Hamilton's themes of legacy and historical narrative. "Knowledge of self" refers to identity formation within the hip-hop community and the importance it places on understanding oneself in relation to society (McCollum, 2019). Hip-hop, as Hamilton demonstrates, is a form of self-expression that is used to differentiate oneself from others and enables audiences to interact with the world through the lens of music as produced by other members of hip-hop culture (McCollum, 2019). Much like an MC or DJ constantly defines their own cultural identity through their engagement with hip-hop and rap, the characters in Hamilton use the same musical genres to define and communicate their individual and collective identities and to differentiate post-independence American culture from British culture. Moreover, the struggles of Hamilton, Burr, and Washington to find their place in a nascent America reflects the way hip-hop artists attempt to situate themselves in their own society through the "knowledge of self" concept. Hamilton is ultimately a story of both the founding fathers and a young America defining the values they stand for and how these differ from other nations, particularly Britain.

\section{Genre as Both Content and Form}

The core conceit in Hamilton, which distinguishes it from other hip-hop and rap musicals (or even other historical musicals), is the fact that it tells the story of the Founding Fathers of America through a musical genre that did not emerge until 200 years later - in other words the focus is on hip-hop as both content and form (Miranda \& McCarter, 2016). Rap was an important aspect of Miranda's musical background and he heavily drew inspiration from it in the development of Hamilton. As Miranda describes it, "for all of its variety of style and subject, rap 
is, at bottom, the music of ambition, the soundtrack of defiance, whether the force that must be defied is poverty, cops, racism, rival rappers, or all of the above" (Miranda \& McCarter, 2016, pg. 21). For Miranda, Hamilton was an opportunity to bring together hip-hop and musical theatre by drawing from stylistic elements associated with hip-hop icons such as DMX or the Furious Five, as well as famous musicals such as South Pacific or The Last Five Years (Miranda \& McCarter, 2016). One element of hip-hop culture that Hamilton integrates into theatre is Kendrick Lamar's style of polysyllabic rap lyrics, which are evident in "Washington on Your Side": "I'm in the cabinet I am / complicit in / Watching him grabbin' at power and kiss it. / If Washington isn't gon' listen / To disciplined dissidents, this is the difference. / This kid is out!" (Miranda, 2015, 1:55-2:02). Another example of multisyllabic rhymes can be found in "NonStop" with the rhyming of "be Socrates" and "mediocrities" (Eastwood \& Hinton, 2016). In contrast to more simplified or basic rap styles, polysyllabic rap is often used in Hamilton to indicate expertise and eloquence through elevated form. For example, Hamilton mainly uses polysyllabic rhyme to demonstrate his wit and eloquence whereas other characters such as his trio of friends (Lafayette, Laurens, Mulligan) or even King George III engage in much simpler, monosyllabic rhymes. It is not just Miranda's lyrics that serve as references though. In "Yorktown", Miranda mimics Busta Rhymes' habit of soft-loud-soft lyrical shouting, where one line is spoken softly, then one loudly, and then back to soft (Miranda \& McCarter, 2016). The systematic spelling out and rhyming of Hamilton's name in "My Shot" is the same cadence as Notorious BIG's "Going Back to Cali": "A-L-E-X-A-N-D-R - we are - meant to be" (Miranda, 2015, 0:43). References to Jay Z and Pharrell are also made in "Schuyler Sisters" with the following lines: "Someone in a rush next to someone lookin' pretty. / Excuse me miss" - a direct reference to their 2009 collaboration "Excuse Me Miss" (Miranda, 2015, 1:20). These 
references, Miranda believes, are integral to Hamilton, as "they're another way of saying that American history can be told and retold, claimed and reclaimed [...]" (Miranda \& McCarter, 2016, pg. 95).

References to musicals, on the other hand, include a nod to the invented words and phrases of West Side Story like "rigatigatum" and "crack-jacko" during "Stay Alive": "Hit "em quick, get out fast / Chick-a-plao!" (Miranda, 2015, 0:57) (Miranda \& McCarter, 2016). Miranda also pays homage to other musicals by including the song "Say No to This" which leverages the traditional musical theatre convention for songs about infidelity. "Say No to This" (where Hamilton cheats on Eliza with Maria Reynolds) is specifically a reference to "Nobody Needs to Know" from the musical The Last Five Years (2001), where, similarly, the main characters break up due to infidelity among other issues (Miranda \& McCarter, 2016). As well, Hamilton was heavily influenced by themes in other legendary musical shows including Sweeney Todd: The Demon Barber of Fleet Street (1979), Jesus Christ Superstar (1970), Evita (1978), and Gypsy (1959) (Miranda \& McCarter, 2016). Gypsy and Sweeney Todd are about "monsters" who have been judged by history, themes that Hamilton explores through its emphasis on history and its retelling; Evita and Jesus Christ Superstar, like Hamilton, started as concept albums and blossomed into successful musicals; and finally, Les Misérables focuses on revolution and on characters defy the rules imposed upon them (Miranda \& McCarter, 2016). Mirada incorporates these themes into Hamilton as a sort of love letter or homage to the genre of historical musical that inspired him. While rap and hip-hop certainly have the most dominant influence on Hamilton there are also still dozens of smaller references to other styles throughout such as vaudeville comedy, Broadway big band, new wave music, art rockers, and more (Miranda, 2015, Genius Lyrics). Finally, Hamilton also contains references to Shakespearean plays. For example, 
in "Take a Break," Hamilton draws parallels between his life and that of Macbeth with the line, "Screw your courage to the sticking place" (Miranda, 2015, 1:03). As well, Miranda includes references to stage directions in "My Shot" with lines such as "Enter me! / (He says in parentheses)" (Miranda, 2015, 4:00). This complex incorporation of musical references is intended not only to educate those less familiar with hip-hop, rap or musical theatre, but to better connect American audiences with the content that they might be more familiar with using specific preceding musical icons, songs, or artists. In other words, Miranda's references to particular cultural works and to broader genre function in the same way as allusion in poetry and literature, that is, as a sense of reward to audiences for recognizing similarities with other works based on their own cultural knowledge.

While Hamilton's rags-to-riches story is by no means unique given that many other musicals and literary works use this narrative structure, it maps particularly well onto the world of hip-hop as many artists of that genre tell similar stories of "starting from the bottom" and growing into fame and fortune, such as Eminem, Drake, or Jay-Z (Kajikawa, 2018). Miranda has actually cited Eminem, a modern rapper who went from being bullied and working several jobs to cover costs for his family to one of the best-selling music artists of all time, as an influence in terms of Hamilton's own journey from modest beginnings and also in the use of polysyllabic rhymes (Miranda, 2015, Genius Lyrics). Hamilton is not only full of references to the hits of some of the greatest hip-hop and rap artists, but also pays homage to other elements of the music environment of NYC that shaped hip-hop culture, such as buskers (Miranda \& McCarter, 2016). In the song "Aaron Burr, Sir", for example, the character John Laurens sets up the next section of rap with the following line, very similar to how buskers would start their own performances: "Yo, yo, yo, yo, yo! / What time is it? / Show time!" (Miranda, 2015, 1:23). Particularly, the call 
and response technique of letting the audience know that it is "show time" is reminiscent of how buskers would draw attention to themselves before a performance.

The hip-hop and rap references, however, remain the strongest and most obvious efforts of Hamilton. The simple rhyme style and cadence of John Laurence's rap introduction in "Aaron Burr, Sir" borrows lines from old school hip-hop where artists often introduce themselves as "I'm [insert name] in the place to be": "Show Time! / Yo! / I'm John Laurens in the place to be!" (Miranda, 2015, 1:31) Another reference to a hip-hop great can be found in "My Shot" which borrows a line from a Mobb Deep song: "Only nineteen but my mind is older" (Miranda, 2015, 0:27) Another convention of hip-hop is what is known as the Big Pun effect whereby several internal rhymes are combined so densely that they feel almost conversational (Miranda \& McCarter, 2016). Appropriate examples of this can be found in the following lines in "My Shot": "I have learned to manage, I don't have a gun to brandish. / I walk these streets famished" (Miranda, 2015, 0:33) or “But Jesus, between all the bleedin' 'n fightin'/ I've been readin' 'n writin"” (4:38). Of all characters, Hamilton uses Big Pun and polysyllabic rhymes the most so that, from a lyrical language perspective, Hamilton is set apart from other characters by his seemingly unrivalled writing ability and intellect (Kajikawa, 2018). This is illustrated by the meeting between Hamilton and his friends Lafayette, Mulligan and Laurens in "My Shot" where the other three have a much simpler and "old school" approach to rapping with predictable beats and rhymes (Kajikawa, 2018). Interestingly, Hamilton's writing ability was indeed advanced; writing enabled him to leave his home country of St. Kitts and Nevis when an American newspaper published an article that he had written which in turn spurned locals to raise the funds to send him to the U.S. colonies for his education (Horwitz, 2016). 


\section{Rap: An Effective Historical Discourse}

Rap as a musical style is particularly well suited for the sheer amount of exposition that Miranda has crammed into the musical, as well as the years of historical content that must be covered (Miranda \& McCarter, 2016). Miranda achieves such an effective distillation of vast historical information because rap is a verbally dense genre of music, or as Miranda puts it, rap simply achieves "more language per measure" (Nereson, 2016). If one were to follow the average pacing of previous Broadway musicals, Hamilton ought to take between 4-6 hours to perform, but instead, because of the selected genre and fast rapping styles of several cast members, Hamilton clocks in at just two and a half hours (Truax, 2020). Two clear examples of the rapid speed required in Hamilton can be seen in Angelica's rap in "Satisfied" where she sings 121 words over the course of 24 seconds, or in "Guns and Ships" where Lafayette covers 19 words in 3 seconds (Truax, 2020). "Guns and Ships" itself actually holds the unofficial record of being the fastest song in a musical (at 6.3 words per second) in what is the fastest-paced musical with 20,000 words in only 2.5 hours (Miranda, 2015, Genius Lyrics). And yet, even with words firing out of the mouths of the actors at this pace, the general meaning and narrative of Hamilton is not lost. While the audience may not catch every word on their first listen, the natural flow, rhyme, and meter of these quick lyrics can be committed to memory more easily, similar to other earworms. The focus on the speed of rap is less about the physical feat and more on how rap allows a faster pace than traditional forms of musical theatre which helps convey more information in less time - a condensed history lesson of sorts. To put the pacing in context, the fastest songs in Hamilton average about 200 words per minute (Libresco, 2015). Now, compare this to Phantom of the Opera's (1986) 1 hour and 40-minute album runtime with 6,789 words or Spring Awakening's (2006) 1 hour runtime with only 4,709 words (Libresco, 2015). That would 
translate to Phantom of the Opera's 68 words per minute or Spring Awakening's 78 words per minute. In fact, if one would sing Hamilton at the same words per minute pacing of Phantom of the Opera it would take almost 6 hours and at the pacing of Spring Awakening it would take about 4 and a half (Libresco, 2015). History needs to be timely and accessible, and this is what Hamilton is trying to emulate.

\section{Redefining Mainstream Culture}

The massive success of Hamilton on Broadway and also in the charts helped redefine what modern hip-hop and rap can be and exposed new audiences to the genre. The culmination of this feat was when Hamilton was awarded the best rap album in 2015 by Billboard (Miranda \& McCarter, 2016). However, since Hamilton caters to but also subverts genre expectations (e.g., blending different musical styles, integrating European influenced hip-hop, articulating contemporary themes through a story set 200 years ago, etc.), the musical is able to connect with audiences that may be less familiar with hip-hop or rap (Kajikawa, 2018). Music researchers have also established that audiences are much more likely to engage with music that shares the acoustic features of their preferred main genre (Barone et al., 2017). Further, different cultures and languages create unique communication structures, patterns and rhythms which often directly influence what is known as the prosodic patterns of speech that are then directly reflected in music from these cultural groups (Barone et al., 2017). On top of familiar acoustic features that a listener tends to seek out in secondary music choices, listening choices are also made based on one's personality that might have predispositions to certain styles or genres based on its evoked emotions (Barone et al., 2017). Psychomusicology studies have demonstrated positive emotional responses are more likely to occur if the listener has prior experience and thus expectations of certain lyrics, music genre, etc. (Susino \& Schubert, 2018). In other words, the 
human ear yearns for what it knows or can expect; elements of mystery can represent fear or danger. For this reason, researchers in the field of psychomusicology emphasize that "patterns of tension and relaxation that are generated by the generation, violation, and resolution of tonal expectations" (Barrett \& Janata, 2016, pg. 235). One example, then, of how Miranda manipulates these hip-hop expectations is by deviating from the standard time signature of rap, 4/4 (4 quarter beats per measure), which is also referred to as common time (Connor, 2017). Instead of using the steady, predictable pattern of 4/4, in "Meet Me Inside," for example, Miranda uses the complex 7/8 time (7 notes of equal duration per measure) causing a certain sense of unpredictability (Connor, 2017). Even within a song, Hamilton does not conform to a rigid time signature or tempo, with individual lines sometimes being dragged out or shortened to make it sound more like natural conversation such as the earlier example from "Meet Me Inside" (Connor, 2017).

\section{Positive Benefits of Arts-Based Field Trips}

While I have established the neurological benefits of musical mnemonics as seen in Hamilton, I wish to further highlight its application in education as the research and my analysis have proven music's capacity for heighten recall and retention among. To explore the academic or pedagogical merits of incorporating multimodal approaches into curriculum through activities such as arts-based field trips, it is important to consider what students can learn from these experiences. Learning does not always have to be measured in the number of names, dates, or figures a student has retained after an academic activity. In fact, learning also includes larger developmental progressions such as social skills, critical thinking, information processing, etc. As will be discussed below, many of these aspects have seen positive improvement for students exposed to arts or culture field trips or those with music incorporated into their curriculum. 
Hamilton is a historical musical intended to retell a core part of America's history in a way that is more compelling than conventional history curriculum. Miranda seems to have made a considerable effort to integrate historical facts and events and even, to some degree, text borrowed from historical documents, as discussed in previous sections. When Miranda finally realized that the story of Alexander Hamilton needed to be told, he reached out to Ron Chernow, the author of Hamilton's biography, Alexander Hamilton, because, as Miranda put it, "I want historians to take this seriously" (Miranda \& McCarter, 2016, pg. 32). While Hamilton certainly gained the attention of many historians, as is evident by their attendance of the show, their reviews of Miranda's creative retelling of history were mixed; while historians pointed out that Hamilton changes and omits key facts, some of them praised the formation of historical musical narrative around the figure of Hamilton (Schuessler, 2020). While Miranda clearly rewrote, reframed and omitted parts of Hamilton's past (and of his contemporaries) that are well established in historical literature, this was a necessity within the strictures of musical theatre and certainly does not deviate from past convention. After all, musical theatre is a form of entertainment and therefore needs to be tailored according to its audience. Miranda took creative license by condensing, rewriting or intentionally overlooking events and timelines to construct a narrative that would be more memorable and understandable. As well, as a homage to the People of Colour heritage of both himself as well as hip-hop, the casting calls for Hamilton prioritized diversity over historically accurate representations of the original ethnicities of the musical's characters. This move suggests that the production sought to reshape how the past has historically been told by rich, straight white men. Miranda wanted to present history in a way wherein Americans who were historically disenfranchised or underrepresented in historical studies could better connect with the story - to see a part of themselves on the stage. In 
Miranda's own words, he believes Hamilton "is a story about America then, told by America now" (Miranda \& McCarter, 2016, pg. 33). The study of history has always been a catalyst for humanity to understand its present state and what the future might hold. It is these themes which Miranda couples with a modern approach to make reflection on historical impact more salient. For this reason, Miranda made sure to present the setting of Hamilton, New York City, in a way

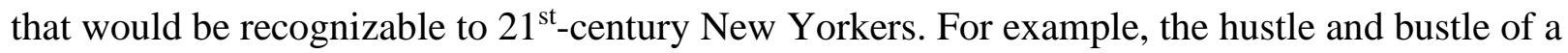
constantly moving city, rife with opportunity, is portrayed quite well in "Schuyler Sister" and is immediately recognizable to a modern audience. (Miranda \& McCarter, 2016).

Miranda's concern with integrating as much historical content into the musical as possible was facilitated by the rap genre, which is particularly well suited for covering the span of several decades in a relatively small amount of time and ensuring that references to historical events stick out. For example, in "You'll Be Back," there is a reference to the Boston Tea Party of 1773 for context: "In your tea which you hurl in the sea when you see me go by" (Miranda, 2015, 0:17). Miranda also attempts to stay true to historical primary sources, pulling words directly from papers, reports or manuscripts in order to reuse words that the characters' historical counterparts actually said or wrote. Two such examples occur in "Right Hand Man" including when Hamilton says, "I wished for a war" or when Washington asks, "Are these the men with which I am to defend America?" (Miranda, 2015, 0:28 \& 2:45). Although the characters are rooted in historical fact and narratives that would be recognizable to students of U.S. history, each character is a creative interpretation of the historical figure. In this way, audience recognizability and relatability motivated key production decisions, such as the selection of hiphop and rap as the primarily musical genres of Hamilton as well as the casting of POC actors for most of the roles. Indeed, this process of retelling and reinterpreting history is the focus of 
"Satisfied," which is a 're-wound' version of "Helpless" and which can be understood as a commentary on the way in which stories can be told from many different perspectives and that history itself has been shaped by many changing narratives (Miranda \& McCarter, 2016).

\section{Teaching Historical Narrative}

The overall story within Hamilton is not just about Hamilton or Eliza's lives but about the ideas of legacy and history. Hamilton is constantly afraid that he will not achieve his ambitious goals and will thus be forgotten. Eliza, in Act I, feels like she is being left out of the narrative of Hamilton's life because her husband is moving too fast ("That Would Be Enough"), but by Act II she actively tries to erase herself from the narrative post-Reynolds Pamphlet ("Burn") (Miranda \& McCarter, 2016). Eliza did truly burn many of her correspondences with Hamilton, their words, meanings, and implications lost to time. However, the narrative arc finally comes full circle in "Who Lives, Who Dies, Who Tells Your Story" when Eliza puts herself back into the narrative and thus shows the importance of historical framing. Washington expresses similar feelings as Hamilton in "History Has Its Eyes On You" when he introduces the idea of "Who lives, who dies, who tells your story" to advise Hamilton about being less compulsive (Miranda $\&$ McCarter, 2016). The greater implementation of the meta plot point on the conventions of historical narrative also primes the audience for information processing. As prodded by the musical's agonies about legacy, the audience is encouraged to be aware of its role in Hamilton's modern legacy and how audience members act as "historians" or interpreters and re-tellers of historical narratives (Harbert, 2018). Perhaps the most poignant moment of this legacy narrative is at the end of "Who Lives, Who Dies, Who Tells Your Story" when Eliza steps into the theatre's spotlight in a meta moment of seeing the audience and her successful maintaining of Hamilton's legacy - a switch from history to historiography to focus on who tells the story rather 
than who the story is about (Nereson, 2016). This seems to have always been Miranda's intention. As he put it, by “ending with Hamilton's afterlife, not his death, the show asks us to think about what we leave behind when we're gone: It invites us to think about legacies (Miranda \& McCarter, 2016, pg. 276).

\section{Musically Connecting Past and Present}

Another reason that Hamilton is well suited for a modern learning environment is that it uses modern language that youth of $21^{\text {st }}$ century America would understand instead of the stilted, archaic language of the 1700s (Miranda \& McCarter, 2016). This is even better reflected in the rap battles (“Cabinet Battle \#1" and "Cabinet Battle \#2"), a hyped form of direct rap conflict which is already very popular on modern social media sites like YouTube, and which even includes the iconic mic drop (Nereson, 2016). Miranda has made it pretty clear in interviews and discussions on hip-hop or rap that many of his musical and creative choices were made as a way to connect with the younger generation of Americans and thus help them understand the founding fathers in a way so that they can help shape the future of America - a future that is theirs (Shisko, 2019). In this way, Hamilton is intended to work as a bridge, creating feelings of kinship which are central to the hip-hop identity. It is a vehicle for cultural citizenship to connect people from all kinds of backgrounds and to give them a voice and sense of belonging in the musical, cultural and political voice of America (Williams, 2018, pg. 490).

As well, the sheer success of the musical Hamilton is proof that hip-hop and rap are now accepted parts of mainstream music (Kajikawa, 2018). But, as discussed in previous sections, Hamilton is crafted in a way that separates it from a large majority of the perhaps more negative expectations around the genre, such as excessive swearing, overt sexual references and themes including drug use or other more taboo themes (Kajikawa, 2018). It is also already clear the 
impact that Hamilton is having on the growing generations of America. As one high school student said after viewing it with their class, "It just made me really proud, and feel good about being American. Like I belong here" (Miranda \& McCarter, 2016, pg. 160). Another student after a Hamilton viewing was recorded as saying, "I've learned so much from this musical that I wouldn't have normally learned in a history class" (Horwitz, 2016, 45:00).

Hamilton not only has a noticeable impact on the most impressionable American demographic but has even moved leading figures like former U.S. President Barack Obama, who said, "Part of what's so powerful about this performance is it reminds us of the vital, crazy, kinetic energy that's at the heart of America - that people who have a vision and a set of ideals can transform the world" (Miranda \& McCarter, 2016, pg. 284). It is very clear through these testimonials and its overwhelming success, that Hamilton's music and narrative have the unique ability to connect America with its past in unprecedented ways. That is exactly what the field of history needs to keep American students engaged.

\section{Reflections on Historiography}

Hamilton's true historical legacy is not nearly as idealistic or concise as the one depicted in Hamilton. Miranda had to take many creative licenses to condense Hamilton's life of about 45 years into an entertaining medium. For example, in Hamilton, Miranda establishes Hamilton's status as an immigrant to be one of his defining features as a commentary on more modern political and social issues about immigrants in America. However, while Hamilton was born in Saint Kitts and Nevis in the Caribbean, at that time in history, he would have been considered an "internal migrant of the British Empire," and as a white man, his immigrant status was not nearly as great of a barrier as Miranda is perhaps suggesting here (Magness, $2017 \mathrm{pg}$. 497). With many of these smaller changes, the musical worked hard to reshape and aid Hamilton's image and 
legacy (Magness, 2017). Even though Hamilton's face adorns the U.S. five-dollar bill, many Americans would be challenged to correctly identify his contributions to the country. The core effort in Hamilton (which is common to the genre of historical musicals) then is to balance entertainment, fiction, and historical accuracy, a struggle that is particularly challenging when attempting to create a narrative that imparts realism while also having characters that dramatically break out into song (Harbert, 2018). One of the common workarounds for such a challenge in historical musicals is to blend and subvert expectations by using more modern musical styles, conventions, and patterns which the audience can connect with better than periodappropriate music or lyrics (Harbert, 2018). This is particularly effective because modern audiences have already formed emotional connections and layers of meanings with the popular music that they are familiar with and thus historical musical composers can easily tap into this while also satisfying Broadway expectations (Harbert, 2018). As previously mentioned, periodappropriate music (such as baroque style waltzes or harpsichord) is typically reserved to represent British characters (i.e., "Farmer Refuted" or King George III's songs) in Hamilton for the effect of stark contrast (Harbert, 2018). Previous scholarly analyses of Hamilton have noted that this conflict between the musical styles of British and American characters mirrors a more recent struggle between musical genres, as hip-hop's history is filled with the search for authenticity that deviates from the conventions of pop music and the expectations of the mainstream (Williams, 2018).

In fact, the timeliness of Hamilton in the modern entertainment sphere comes from what some scholars believe to be a new dominance of historicism, a movement in which the cultural context of a text is considered to be as important, or even more important, as the text itself (Styrt, 2018). In this sense, Miranda can be understood as taking a historicist approach in Hamilton by 
reframing the narrative to make American history more accessible to students in today's cultural context. Many students are often put off by studying history due to events that are complex, seem distant and are often filled with what appear to be boring minutiae. Instead, Hamilton generalizes what was a dense part of American history for ease of comprehension, while playing off of the general knowledge of the time period (Styrt, 2018).

Studies like Greene et al. (2015) have demonstrated the positive educational impact of cultural field trips such as museums or live theatre on students. In particular, trips to see a live play or musical versus reading a book or attending a lecture have been found to greatly improve students' abilities to recall and understand given works (Greene et al., 2015). Furthermore, students who had more opportunities to participate in cultural field trips were able to better read the emotions of their peers or the performers and were more tolerant when evaluating the original work, even if it might go against their interests or expectations (Greene et al., 2015). In addition to their immediate benefits, cultural field trips have also been found to cultivate a stronger interest in future musical attendances, a greater love for music, and some of the critical thinking skills associated with musicians (Greene et al., 2018). Such continued exposure is also able to positively impact the academic performance of attending students, in part due to improved recall, retention, and comprehension of viewed materials. To put this into context, researchers like Jægar \& Møllegarrd (2017) studied identical twins who grew up with differing exposures to cultural activities. They found that the participants who engaged more with these cultural activities were more likely to have improved grades and a higher chance of graduating high school (Jægar \& Møllegarrd, 2017). These positive benefits also have a long-term capacity. Academic improvements were noted two years after the tested period of multiple arts-based field strips over non-participating students (Pogue, 2021). Further, studies like Goldstein \& Winner 
(2012) or Lee et al (2015) established positive social-emotional benefits, whereas other studies like Pogue (2021) noted that repeated arts-based field trips are more likely to facilitate future interest in the arts and encouraged participants to be more accepting of differing opinions and viewpoints. This type of arts-based education was also proven to improve general school behavior, such as school attendance while decreasing behavioral infractions and improving conscientiousness as noted in self-administered surveys (Pogue, 2021). Further, teachers themselves provided overwhelmingly positive responses in studies like Pogue's (2021), which encouraged students to be more artistic. As Mitchell at al. state in their 2019 study on the positive impacts of such arts-based field strips: "the qualitative data gathered from students suggested that participation in theater arts can impact a student's attitude toward learning, increase engagement in school, and improve self-confidence” (Mitchell et al., 2019, pg. 1).

Overall, the positive educational and developmental benefits of cultural field trips or culturally influenced educational approaches, can be understood in terms of Pierre Bourdieu's idea of cultural capital, or an individual's familiarity with the culture practices and classificatory systems (such as "high culture" and "popular culture") of a certain society, which he sees as a key determining factor in enabling positive developments in academic, social and economic realms (Kisida, 2015). As Kisida explains, Bourdieu noted that acquisition of cultural capital is often lacking in disadvantaged families due to economic or social barriers to high culture (Kisida, 2015). Naturally, then, it follows that students with more cultural capital are more likely to be interested in arts-based field trips or cultural activities versus disadvantaged families (Kisida, 2015). Therefore, in an effort to more evenly distribute cultural capital, it is incredibly vital that all students receive proper cultural education through processes such as musical theatre trips (Kisida, 2015). Unfortunately, due to funding issues, particularly with schools with 
dominant student populations of minority populations, many arts-based school programs are seeing cutbacks in recent years (Kisida et al., 2015). Since the impacts of arts-based field trips or education are often less measurable, educators have met difficulties convincing policymakers or educational school boards to allocate the appropriate funds and resources (Kisida et al., 2015). Thus, using examples such as Hamilton as a case study to demonstrate how students can improve their creativity, self-expression, and emotional intelligence is important to the future incorporation of musical mnemonics in educational settings, as well as the continuation of artsbased field trips (Kisida et al., 2015).

As discussed in my literature review, there is a significant body of research that has pointed to the success of processing, recalling, and comprehending knowledge when combined with music (Morrongiello \& Roes, 1990). Through a unique modal connection, information is more effectively stored in long-term memory for better retention and can be more easily called upon when the same bridge (e.g., music, lyrics, songs, etc.) is triggered (Morrongiello \& Roes, 1990). Such research indicates that there are important differences in the human ability to memorize verbal versus nonverbal communication, which is particularly relevant for creating learning environments that support a variety of different learning approaches (Morrongiello \& Roes, 1990). Learning environments that integrate insights from studies such as McElhinney \& Annett's (1996) are potentially more effective for enabling long-term recall and retention.

The literature also confirms that music has the capacity to emotionally move people in ways that are difficult to do through more commonplace educational materials. As the previous literature review revealed, tapping into such potential through tools like musical mnemonics, music integration into teaching methods or through the incorporation of regular arts-based field traps is largely undeveloped in modern American curriculum. While there is proven scientific 
merit to the efficacy of musical mnemonics, schools have seen limited integration of multimodal teaching approaches or increased exposure to entertainment forms, like musicals, that could greatly improve learning abilities. Historical musicals, like Hamilton, attempt to capitalize on the cross-sectional of entertainment and education by pseudo-lecturing to audiences in a way that is fresh and entertaining. The humanities, which continue to see declining levels of interest in engagement from students, require new life to connect with modern students. The literature strongly suggests that one way to address these challenges would be to reimagine historical knowledge and other kinds of content through new forms of entertainment with the goal of education so as to engage a diverse and changing audience. However, while there are generalized studies which offer research findings on the benefits of music-based educational materials and experiences, relatively little scholarly attention has been given to the analysis of the differential efficacy in terms of comprehension and retention between, for example, watching Hamilton versus reading a textbook about the American Revolution. Therefore, further research or study into this field should attempt such direct comparison in order to demonstrate either the value of one approach over the other, or point towards the benefits of an integrated, multimodal approach. Such future studies may be able to identify certain types of musicals that are more effective than others, evaluate the efficacy of plays versus musicals (or other forms of art and culture), and then synthesize the findings into comprehensive theories on the use of music or musical mnemonics in a learning environment. 


\section{CONCLUSION}

Given its tremendous success in the last few years, the legacy of Hamilton is impacting children in America and other countries but is bringing greater attention to the importance of preserving, engaging with and re-telling history. Since Hamilton's 2015 debut, historical sites strongly connected to the musical like the Schuyler-Hamilton house, Schuyler Mansion, and Hamilton Grange have seen a huge boost in attendance (Skala, 2018). This suggests that Hamilton is not only significant in terms of a one-time, spatial engagement with the historical material but also moves audiences enough to pursue the musical's real-life physical history.

Another important aspect to consider when evaluating the pedological value of musical theatre, particularly Hamilton, is the various emotional tools that were previously discussed in this study may also be helpful in regulating mood (Garrido et al., 2016). Mental health issues can often act as barriers for social connections, particularly in developing children, and thus it is natural that therapeutic avenues, such as listening to music, are more likely to improve one's mood (Garrido et al., 2016). Further, listening to music, especially in a group setting, can help bridge feelings of isolation or lack of social engagement (Garrido et al., 2016). In musical theatre, the energy of the audience, the modulation of the musical based on audience reactions, and other such facets of live entertainment also elevate the experience beyond just what one would hear from the album (Garrido et al., 2016).

This case study of Hamilton has considered the elements of music theory, as well as genre and musical theatre conventions to pinpoint exactly how musical mnemonics are at play in Hamilton that aid an audience's understanding of the plot and thus its historical content. Further, by discussing Hamilton's use of narrative, both historical and theatrical, this study has identified how the musical is able to teach audiences about the form of musical theatre itself as well as how 
to reflect on the creation and study of history as a subject. Finally, as a hip-hop and rap musical, Hamilton is a unique look into hip-hop and rap culture through musical references, musical genre choices, and other strategies in order to connect those two genres to the mainstream of modern American society. In this way, audiences with diverse musical preferences are able to learn about the history of the musical forms used in Hamilton alongside the historical narrative that is retold through those musical forms. The result is a memorable and entertaining historical look at a story central to the founding of America, told in a way that modern audiences, including children, can connect with and understand to foster increased appreciation of history and creative forms like musicals. 


\section{WORKS CITED}

Apel, W. (1944). Harvard Dictionary of Music (Second). Belknap Press of Harvard University Press.

Barone, M. D., Bansal, J., \& Woolhouse, M. H. (2017). Acoustic Features Influence Musical Choices Across Multiple Genres. Frontiers in Psychology, 8. https://doi.org/10.3389/fpsyg.2017.00931.

Barrett, F. S., \& Janata, P. (2016). Neural responses to nostalgia-evoking music modeled by elements of dynamic musical structure and individual differences in affective traits. Neuropsychologia, 91, 234-246. https://doi.org/10.1016/j.neuropsychologia.2016.08.012.

Bell, J., \& Chicurel, S. R. (2008). Music Theory for Musical Theatre. The Scarecrow Press.

Binder, J. R., \& Desai, R. H. (2011). The neurobiology of semantic memory. Trends in Cognitive Sciences, 15(11), 527-536. doi:10.1016/j.tics.2011.10.001.

Blanchard, B. (1999). The Social Significance of Rap \& Hip-Hop Culture. Ethics of Development in a Global Environment (EDGE): 'Poverty \& Prejudice: Media and Race. https://hiphoparchive.org/sites/default/files/the_social_significance_of_rap_hip_hop_cultur e.pdf.

Bribitzer-Stull, M. (2015). Understanding the Leitmotif : From Wagner to Hollywood Film Music. Cambridge University Press. 
Britannica, The Editors of Encyclopaedia. "Rap". Encyclopedia Britannica, 18 Jun. 2020, https://www.britannica.com/art/rap. Accessed 8 July 2021.

Brooman, J., \& Culpin, C. (2008). School history scene: The unique contribution of theatre to history teaching. Teaching History, 108, 55-59. Retrieved May 25, 2021, from http://ezproxy.lib.ryerson.ca/login?url=https://www-proquestcom.ezproxy.lib.ryerson.ca/scholarly-journals/school-history-scene-unique-contributiontheatre/docview/213412395/se-2?accountid=13631.

Connor, M. (2017, February 7). How 'Hamilton' Put the Music Back at the Center of the Musical. Soundfly. https://flypaper.soundfly.com/discover/music-of-hamilton-musical/.

Davies, R. R., Graham, K. S., Xuereb, J. H., Williams, G. B., \& Hodges, J. R. (2004). The human perirhinal cortex and semantic memory. European Journal of Neuroscience, 20(9), 2441-2446. doi:10.1111/j.1460-9568.2004.03710.x.

Dellacherie, D., Roy, M., Hugueville, L., Peretz, I., \& Samson, S. (2011). The effect of musical experience on emotional self-reports and psychophysiological responses to dissonance. Psychophysiology, 48(3), 337-349. https://doi.org/10.1111/j.1469-8986.2010.01075.x

Eastwood, J., \& Hinton, E. (2016, June 6). How does 'Hamilton,' the non stop, hip-hop Broadway sensation tap rap's master rhymes to blur musical lines? The Wall Street Journal. http://graphics.wsj.com/hamilton/. 
Eerola, T., Friberg, A., \& Bresin, R. (2013). Emotional expression in music: contribution, linearity, and additivity of primary musical cues. Frontiers in Psychology, 4, 487. https://doi.org/10.3389/fpsyg.2013.00487.

Florick, L., Greene, J. P., Levenberg, R., \& Pogue, R. (2021). The benefits of multiple arts-based field trips. Phi Delta Kappan, 102(8), 26-29. doi:10.1177/00317217211013933.

Garrido, S., Schubert, E., \& Bangert, D. (2016). Musical prescriptions for mood improvement: An experimental study. The Arts in Psychotherapy, 51, 46-53. https://doi.org/10.1016/j.aip.2016.09.002.

Goldstein, T. R., \& Winner, E. (2012). Enhancing Empathy and Theory of Mind. Journal of Cognition and Development, 13(1), 19-37. https://doi.org/10.1080/15248372.2011.573514.

Gomez, P., \& Danuser, B. (2007). Relationships between musical structure and psychophysiological measures of emotion. Emotion, 7(2), 377-387. https://doi.org/10.1037/1528-3542.7.2.377.

Greene, J. P., Erickson, H. H., Watson, A. R., \& Beck, M. I. (2018). The Play’s the Thing: Experimentally Examining the Social and Cognitive Effects of School Field Trips to Live Theater Performances. Educational Researcher, 47(4), 246-254. https://doi.org/10.3102/0013189x18761034.

Greene, J. P., Hitt, C., Kraybill, A., \& Bogulski, C. A. (2015). Learning from Live Theater. Education Next, 15(1). https://www.educationnext.org/learning-live-theater/. 
Greene, J. P., Kisida, B., \& Bowen, D. H. (2014). The Educational Value of Field Trips. Education Next, 14(1). Retrieved May 20, 2021, from http://ezproxy.lib.ryerson.ca/login?url=https://www-proquestcom.ezproxy.lib.ryerson.ca/scholarly-journals/educational-value-fieldtrips/docview/1471028763/se-2?accountid=13631.

Harbert, E. (2018). Hamilton and History Musicals. American Music, 36(4), 412-428. https://www.jstor.org/stable/10.5406/americanmusic.36.4.0412.

Hayes, B. K., Ramanan, S., \& Irish, M. (2018). "Truth be told" - semantic memory as the scaffold for veridical communication. Behavioral and Brain Sciences, 41. doi:10.1017/s0140525x17001364.

Hip-Hop: A Culture of Vision and Voice. The Kennedy Center. (n.d.). https://www.kennedycenter.org/education/resources-for-educators/classroom-resources/media-andinteractives/media/hip-hop/hip-hop-a-culture-of-vision-and-voice/.

Ho, H. (2017, July 16). The Musical (Non-Lyrical) Brilliance of Hamilton's Hip-Hop Vernacular. HowlRound Theatre Commons. https://howlround.com/musical-non-lyricalbrilliance-hamiltons-hip-hop-vernacular.

Hunter, P. G., Schellenberg, E. G., \& Schimmack, U. (2010). Feelings and perceptions of happiness and sadness induced by music: Similarities, differences, and mixed emotions. Psychology of Aesthetics, Creativity, and the Arts, 4(1), 47-56. https://doi.org/10.1037/a0016873. 
Juslin, P. N., \& Sloboda, J. A. (Eds.). (2010). Handbook of Music and Emotion: Theory, Research, Applications (Ser. Series in Affective Science). Oxford University Press.

Jæger, M. M., \& Møllegaard, S. (2017). Cultural capital, teacher bias, and educational success: New evidence from monozygotic twins. Social Science Research, 65, 130-144. https://doi.org/10.1016/j.ssresearch.2017.04.003.

Kajikawa, L. (2018). "Young, Scrappy, and Hungry”: Hamilton, Hip-hop, and Race. American Music, 36(4), 467-486. https://www.jstor.org/stable/10.5406/americanmusic.36.4.0467.

Kisida, B. (2015). The Educational Benefits of Cultural Institutions (Master's thesis, University of Arkansas). ProQuest Dissertations Publishing. Retrieved May 20, 2021, from http://ezproxy.lib.ryerson.ca/login?url=https://www-proquestcom.ezproxy.lib.ryerson.ca/dissertations-theses/educational-benefits-culturalinstitutions/docview/1696782324/se-2?accountid=13631.

Kisida, B., Bowen, D. H., \& Greene, J. P. (2015). Measuring critical thinking: Results from an art museum field trip experiment. Journal of Research on Educational Effectiveness, 9(Sup1), 171-187. doi:10.1080/19345747.2015.1086915.

Laske, O. E. (1977). Musicology and Psychomusicology: Two Sciences of Music. Psychology of Music, 5(2), 10-22. https://doi-org.ezproxy.lib.ryerson.ca/10.1177\%2F030573567752002.

Lee, B. K., Patall, E. A., Cawthon, S. W., \& Steingut, R. R. (2015). The Effect of Drama-Based Pedagogy on PreK-16 Outcomes. Review of Educational Research, 85(1), 3-49. https://doi.org/10.3102/0034654314540477. 
Lewin, T. (2013, October 30). As Interest Fades in the Humanities, Colleges Worry. The New York Times. https://www.nytimes.com/2013/10/31/education/as-interest-fades-in-thehumanities-colleges-worry.html.

Libresco, L. (2015, October 5). 'Hamilton' Would Last 4 To 6 Hours If It Were Sung At The Pace Of Other Broadway Shows. FiveThirtyEight. https://fivethirtyeight.com/features/hamiltonis-the-very-model-of-a-modern-fast-paced-musical/.

Light, A. and Tate, . Greg. "Hip-hop." Encyclopedia Britannica, February 19, 2021. https://www.britannica.com/art/hip-hop.

Magness, P. W. (2017). Alexander Hamilton as Immigrant: Musical Mythology Meets Federalist Reality. The Independent Review, 21(4), 497-508. https://www.jstor.org/stable/26314791.

McCollum, S. (2019, October 30). Hip-Hop: A Culture of Vision and Voice. The Kennedy Center. https://www.kennedy-center.org/education/resources-for-educators/classroomresources/media-and-interactives/media/hip-hop/hip-hop-a-culture-of-vision-and-voice/.

McElhinney, M., \& Annett, J. M. (1996). Pattern of efficacy of a musical mnemonic on recall of familiar words over several presentations. Perceptual and Motor Skills, 82(2), 395-400. doi:10.2466/pms.1996.82.2.395.

Miller, S. M. (1981). Predictability And Human Stress: Toward A Clarification Of Evidence And Theory. Advances in Experimental Social Psychology, 203-256. https://doi.org/10.1016/s0065-2601(08)60373-1.

Miranda, L. (2015). Hamilton: an American Musical [MP3]. New York: Atlantic Records. 
Miranda, L.-M. (2015). Hamilton: An American Musical (Original Broadway Cast Recording) by Lin-Manuel Miranda. Genius. https://genius.com/albums/Lin-manuelmiranda/Hamilton-an-american-musical-original-broadway-cast-recording.

Miranda, L.-M., \& McCarter, J. (2016). Hamilton: The Revolution (First). Melcher Media.

Morrongiello, B. A., \& Roes, C. L. (1990). Children's memory for new songs: Integration or independent storage of words and tunes? Journal of Experimental Child Psychology, 50(1), 25-38. doi:10.1016/0022-0965(90)90030-c.

Mitchell, D. R., Brooks, M. R., \& Estes, J. S. (2019). Effects of an After-School Musical Theater Program on Student Attendance, Behavior, Academic Achievement, and Social and Emotional Skills (Order No. 27664513). Available from ProQuest Dissertations \& Theses A\&I; ProQuest Dissertations \& Theses Global. (2322131244). http://ezproxy.lib.ryerson.ca/login?url=https://www-proquestcom.ezproxy.lib.ryerson.ca/dissertations-theses/effects-after-school-musical-theaterprogram-on/docview/2322131244/se-2?accountid=13631.

Nereson, A. (2016). Hamilton 's America: An Unfinished Symphony with a Stutter (Beat). American Quarterly, 68(4), 1045-1059. https://doi.org/10.1353/aq.2016.0080.

Olowoyo, O., \& Aminu, S. (2019). Socio, Economic, and Political Significance of Rap Culture on African Americas. International Journal of African Society, 7(2), 25-33. https://www.eajournals.org/wp-content/uploads/Socio-Economic-and-Political$\underline{\text { Significance-of-Rap-Culture-on-African-Americans.pdf. }}$ 
Pralus, A., Belfi, A., Hirel, C., Lévêque, Y., Fornoni, L., Bigand, E., .. Caclin, A. (2020). Recognition of musical emotions and their perceived intensity after unilateral brain damage. Cortex, 130, 78-93. https://doi.org/10.1016/j.cortex.2020.05.015.

Santayana, G. (1980). Reason in Common Sense: The Life of Reason (Vol. 1). Unabridged Dover Press.

Schrader, V. (2019). 'Who Tells Your Story?': Narrative Theory, Public Memory, and the Hamilton Phenomenon. New Theatre Quarterly, 35(3), 261-274. doi:10.1017/S0266464X19000265.

Schuessler, J. (2020, July 6). 'Hamilton' and the Historical Record: Frequently Asked Questions. New York Times. https://www-proquestcom.ezproxy.lib.ryerson.ca/docview/2420306660?pq-origsite=summon.

Schutz, M. (2017). Acoustic Constraints and Musical Consequences: Exploring Composers' Use of Cues for Musical Emotion. Frontiers in Psychology, 8. https://doi.org/10.3389/fpsyg.2017.01402.

Shishko, B. (2019). Lin-Manuel Miranda: Hamilton, a New Era of Broadway Musicals (thesis). International Research Journal. Retrieved from https://thesis-journal.net/wpcontent/uploads/2019/06/Besmir-Shishko.pdf.

Skala, C. (2018, July 10). The Hamilton Effect: How One Musical Made the Founding Fathers Cool, and What it Means for Historic Sites and the Academic World (thesis). University of New Hampshire Scholars Repository. Retrieved from https://scholars.unh.edu/honors/435. 
Styrt, P. G. (2018). Toward a Historicism of Setting: Hamilton and American History. Modern Drama, 61(1), 1-19. https://doi.org/10.3138/md.0902.

RadicalMedia, The John D. \& Catherine MacArthur Foundation (Producers) \& Horwitz, A. (Director). (2016) Hamilton's America [Video file]. Retrieved from https://www.youtube.com/watch?v=Ivv_xOsdgK8.

Travis, M. L. (2017). Hamilton: A Musical Analysis of Ensemble Function (dissertation). OpenCommons@UConn. Retrieved from https://opencommons.uconn.edu/dissertations/1399/.

Susino, M., \& Schubert, E. (2018). Musical emotions in the absence of music: A cross-cultural investigation of emotion communication in music by extra-musical cues. PLoS ONE, 15(11). https://doi.org/10.1371/journal.pone.0241196.

Taylor, J. A. (1982). Psychomusicology: Perceptual/Cognitive Research with Implications for the Composer and Performer. College Music Symposium, 22(1), 90-103. https://www.jstor.org/stable/40374144.

Truax, A. (2020, July 12). From Stage, Cast Album, To Film: A Deep Dive In What Makes 'Hamilton' Great - Part 2 -. mxdwn Movies. https://movies.mxdwn.com/feature/fromstage-cast-album-to-film-a-deep-dive-in-what-makes-hamilton-great-part-2/.

Tsekoura, K., \& Foka, A. (2020). Classification of EEG signals produced by musical notes as stimuli. Expert Systems with Applications, 159, 113507. https://doi.org/10.1016/j.eswa.2020.113507. 
Williams, J. A. (2018). "We Get the Job Done”: Immigrant Discourse and Mixtape Authenticity in The Hamilton Mixtape. American Music, 36(4), 487-506.

https://www.jstor.org/stable/10.5406/americanmusic.36.4.0487. 